Tecnología y

Ciencias $\stackrel{\mho}{\varpi}$ Aua
2022, Instituto Mexicano de Tecnología del Agua Open Access bajo la licencia CC BY-NC-SA 4.0 (https://creativecommons.org/licenses/by-nc$\mathrm{sa} / 4.0 /)$

DOI: $10.24850 / \mathrm{j}$-tyca-2022-02-01

Artículos

\title{
Marco conceptual y metodológico del riesgo por sequía y sus componentes: amenaza, exposición y \\ vulnerabilidad
}

\section{The conceptual and methodological framework of drought risk and its components: Hazard, exposure and vulnerability}

Heidy Viviana Castellano-Bahena ${ }^{1}$, ORCID: https://orcid.org/0000-00021387-516X

David Ortega-Gaucin², ORCID: https://orcid.org/0000-0002-5336-7442

${ }^{1}$ Instituto Mexicano de Tecnología del Agua, Jiutepec, Morelos, México, heidyviv78@gmail.com

2Instituto Mexicano de Tecnología del Agua, Jiutepec, Morelos, México, dortega@tlaloc.imta.mx

Autor para correspondencia: David Ortega-Gaucin, dortega@tlaloc.imta.mx 
Teccnología y

Ciencias $\stackrel{\Xi}{\Im}$ Agua
2022, Instituto Mexicano de Tecnología del Agua

Open Access bajo la licencia CC BY-NC-SA 4.0

(https://creativecommons.org/licenses/by-nc$\mathrm{sa} / 4.0 /)$

\section{Resumen}

La reducción del riesgo de sequía y sus impactos directos e indirectos ha cobrado relevancia mundial durante las últimas décadas. En este trabajo se presenta una revisión de las herramientas conceptuales y metodológicas básicas para analizar el riesgo por sequía en un sistema determinado. Se describen los componentes fundamentales del riesgo, concebido principalmente como una función de la amenaza (o peligro específico, que en este caso es el fenómeno de la sequía); la exposición (personas, propiedades, medios de vida y sistemas que están sujetos a daños y pérdidas potenciales debido al peligro), y la vulnerabilidad (representada por las condiciones socioeconómicas y ambientales del sistema que lo hacen susceptible de sufrir daños). Se explican los conceptos y definiciones asociados con estos componentes, y se presentan los métodos y modelos matemáticos más usuales para calcularlos. Se concluye que, dada la gran diversidad de enfoques, conceptos y métodos para determinar el riesgo por sequía, queda a criterio del investigador o evaluador la selección del más apropiado en función del enfoque adoptado, la información disponible, y el contexto u objetivo de la investigación.

Palabras clave: gestión del riesgo, fenómenos extremos, sequía, cambio climático, vulnerabilidad, capacidad de adaptación.

\section{Abstract}

Drought risk reduction and its direct and indirect impacts have gained worldwide relevance during the last decades. This paperpresents a review 
Tecnología y

Ciencias $\stackrel{\unlhd}{\unlhd}$ gua
2022, Instituto Mexicano de Tecnología del Agua

Open Access bajo la licencia CC BY-NC-SA 4.0 (https://creativecommons.org/licenses/by-nc$\mathrm{sa} / 4.0 /)$

of the basic conceptual and methodological tools to analyze the drought risk in a given system. The fundamental components of risk are described, conceived primarily as a function of hazard (or specific danger, which in this case is the drought phenomenon); exposure (people, property, livelihoods, and systems that are subject to potential damage and loss due to hazard), and vulnerability (represented by the socio-economic and environmental conditions of the system that make it susceptible to suffering damage). The concepts and definitions associated with these components are explained and the most usual mathematical methods and models for calculating them are presented. It is concluded that, given the great diversity of approaches, concepts, and methods to determine drought risk, it is at the discretion of the researcher or evaluator the selection of the most appropriate depending on the approach adopted, the information available, and the objective or investigation context.

Keywords: Risk management, extreme phenomena, drought, climate change, vulnerability, adaptive capacity.

Recibido: 25/02/2020

Aceptado: $13 / 02 / 2021$

\section{Introducción}


Tecnología y

Ciencias Agua
2022, Instituto Mexicano de Tecnología del Agua

Open Access bajo la licencia CC BY-NC-SA 4.0 (https://creativecommons.org/licenses/by-nc$\mathrm{sa} / 4.0 /)$

En décadas recientes, los desastres provocados por fenómenos naturales han aumentado en el mundo como resultado principalmente del incremento en la vulnerabilidad de la población, y sólo en parte por cambios en las características del peligro mismo (IPCC, 2012). La mayor exposición de la población a fenómenos hidrometeorológicos y climáticos extremos ha resultado en mayor número de desastres. Por ello, el impacto de los desastres en las actividades humanas ha sido un tema tratado en los últimos años en un amplio número de publicaciones, las cuales han sido desarrolladas desde diversas disciplinas que han conceptualizado las componentes del riesgo en formas diferentes, aunque en la mayoría de los casos de una manera similar (p. ej., UNDRO, 1979; Cardona, 1985; Cardona, 2001; Schneiderbauer \& Ehrlich, 2004; Davis, 2004; Jordaan, 2006; Burg, 2008). En términos generales, la mayoría de las propuestas conceptuales coinciden en señalar que el riesgo ante los desastres puede reducirse si se entiende como el resultado de relacionar la amenaza o peligro, es decir, la probabilidad de ocurrencia de un evento específico, y la vulnerabilidad de los elementos expuestos, o factor interno de selectividad de la severidad de los efectos sobre dichos elementos (Figura 1a). Algunos trabajos relacionados con esta concepción del riesgo son, por ejemplo, los realizados por Yen (1971); Cardona (1985); Cardona (1993); Blaikie, Cannon, Davis y Wisner (1994); Wisner, Blaikie, Cannon y Davis (2003), y Tsakiris (2007). Esta concepción del riesgo ha sufrido algunos cambios, pues, por ejemplo, en el quinto informe de evaluación del Panel Intergubernamental de Expertos sobre el Cambio Climático (IPCC, 2014) se determinó que los riesgos del cambio climático provienen 
Tecnología y

Ciencias $\stackrel{\mho}{\mho}$ Agua
2022, Instituto Mexicano de Tecnología del Agua

Open Access bajo la licencia CC BY-NC-SA 4.0 (https://creativecommons.org/licenses/by-nc$\mathrm{sa} / 4.0 /)$

del solapamiento entre la vulnerabilidad (falta de preparación), la exposición (personas o bienes en situación de riesgo), y los peligros (que desencadenan fenómenos o tendencias climáticas), como se muestra en la Figura $1 \mathrm{~b}$.

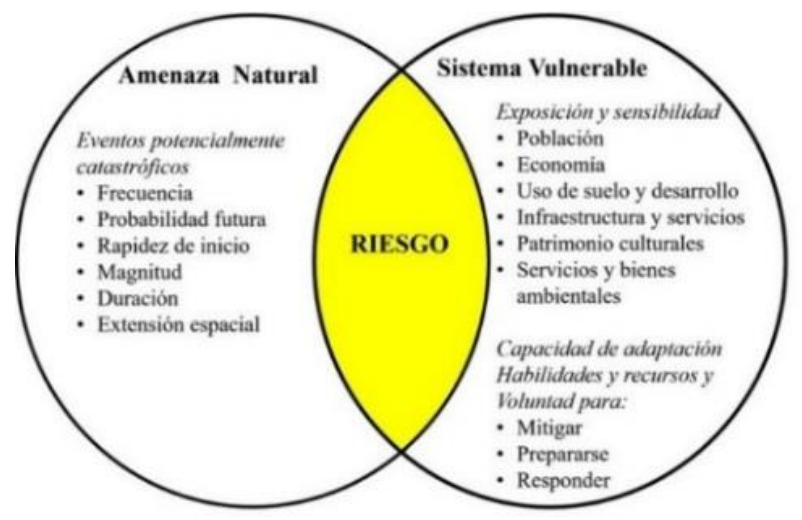

(a)

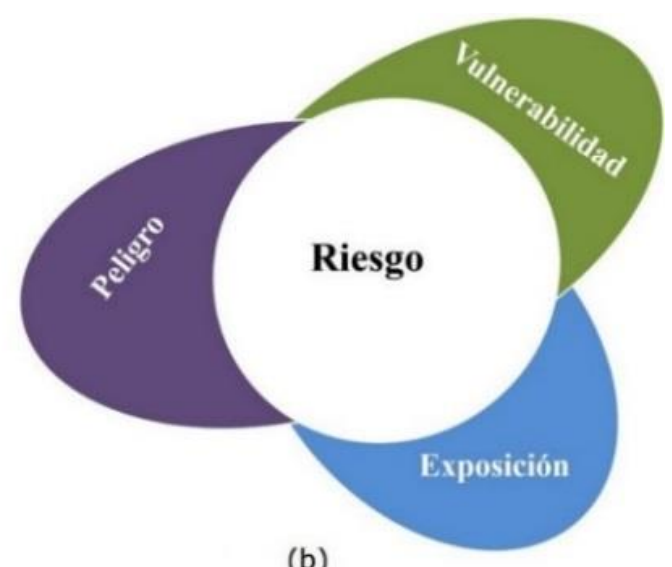

(b)

Figura 1. a) Interacción del riesgo con la amenaza y la vulnerabilidad;

b) interacción del riesgo con la amenaza (peligro), la vulnerabilidad y la exposición. Fuente: adaptada Wood (2011) e IPCC (2014).

Cada uno de los componentes mencionados puede ser objeto de medidas selectivas que contribuyan a reducir los riesgos (Ortega-Gaucin, López, \& Arreguín, 2016). Existen algunos trabajos que describen conceptual y metodológicamente la interacción de los componentes del riesgo (sin centrarse en el análisis de una amenaza o peligro específico), como son los realizados por Cardona (1993), Blaikie et al. (1994), Hoddinott y Quisumbing (2003), BID (2003), Schneiderbauer y Ehrlich (2004), Jordaan (2006), Tsakinis 
Teccnología y

Ciencias $\stackrel{\unlhd}{\unlhd}$ gua
2022, Instituto Mexicano de Tecnología del Agua

Open Access bajo la licencia CC BY-NC-SA 4.0 (https://creativecommons.org/licenses/by-nc$\mathrm{sa} / 4.0 /)$

(2007), Birkmann (2007), y Welle y Birkmann (2015), entre otros. Sin embargo, hablando específicamente del riesgo por sequía, encontramos que la revisión de modelos matemáticos para calcularlo es limitada, pues por lo general las investigaciones se centran en el análisis de sólo un componente del riesgo, ya sea la amenaza o la vulnerabilidad, sin abordar teórica ni metodológicamente la interacción entre ambas variables. Algunos de estos trabajos son los realizados por Gibbs, Maher y John (1967); Bergaoui y Alouini (2001); Bhuiyan (2004); Boken (2005); Narasimhan y Srinivasan (2005); Velasco, Ochoa y Gutiérrez (2005); Chandrasekar, Sai, Roy, Jayaraman y Krishnamoorthy (2009), y Tsakiris et al. (2013). En este contexto, el presente artículo tiene como objetivo hacer una revisión y describir conceptual y metodológicamente las maneras más usuales para evaluar la amenaza, exposición, vulnerabilidad y riesgo de sequía. Así, la aportación del trabajo consiste en proporcionar, de manera concisa, un panorama amplio que sirva de base para la evaluación del riesgo ante este peligro natural. En los siguientes apartados se describen a detalle cada uno de los componentes del riesgo: se inicia por la amenaza, donde se presentan los principales conceptos relacionados con el fenómeno de la sequía, como son los tipos de sequía identificados en la literatura, y los métodos más comunes para caracterizar y evaluar la severidad del fenómeno; posteriormente se analiza el tema de la exposición, en el cual se describe el concepto, sus dimensiones fundamentales y los indicadores utilizados para medirla; luego se detalla la 
Tecnología y

Ciencias $₫$ Agua
2022, Instituto Mexicano de Tecnología del Agua

Open Access bajo la licencia CC BY-NC-SA 4.0 (https://creativecommons.org/licenses/by-nc$\mathrm{sa} / 4.0 /)$

vulnerabilidad, incluyendo las definiciones más usuales, sus componentes, características y métodos para calcularla; después se puntualizan las diferentes definiciones de riesgo y los modelos matemáticos que se utilizan para determinarlo de manera cuantitativa; por último se presentan algunas consideraciones sobre los conceptos analizados y las conclusiones derivadas de la investigación.

\section{Amenaza o peligro hidrometeorológico}

La amenaza o peligro hidrometeorológico es un proceso o fenómeno de origen atmosférico, hidrológico u oceanográfico que puede ocasionar la muerte, lesiones u otros impactos a la salud, al igual que daños a la propiedad, la pérdida de medios de sustento y de servicios, trastornos sociales y económicos, o daños ambientales (UNISDR, 2009). Por lo general, la amenaza se estima con información meteorológica o climática histórica, y se representa por la probabilidad de que ocurra un fenómeno meteorológico o climático particular (p. ej., ciclón tropical, Iluvia torrencial, sequía, etc.). En este caso, el peligro que nos interesa es el fenómeno de la sequía entendida en su sentido más amplio, es decir, aquella disminución severa y prolongada de la lluvia que es capaz de 
Tecnología y

Ciencias $\stackrel{\mho}{\varpi}$ Agua
2022, Instituto Mexicano de Tecnología del Agua

Open Access bajo la licencia CC BY-NC-SA 4.0

(https://creativecommons.org/licenses/by-nc$\mathrm{sa} / 4.0 /)$

provocar graves desequilibrios hidrológicos, y afectar las actividades humanas y los ecosistemas (OMM \& GWP, 2006). Así, el peligro por sequía se refiere a la probabilidad de que ocurra un evento de sequía en un espacio y tiempo determinados con suficiente intensidad como para producir daños. Los valores del peligro varían de una región a otra y dependen de las características específicas del fenómeno estudiado (Magaña, 2013). En los siguientes apartados se describen las definiciones y tipos de sequía, sus parámetros y los principales métodos para determinar sus características (duración, magnitud, severidad, extensión espacial, etc.).

\section{Definición y tipos de sequía}

La sequía se inicia en su mayoría por precipitación deficiente y es considerada como un fenómeno natural relacionado con la variabilidad climática en una región (Tsakiris et al., 2013). Hay muchas definiciones de sequía, algunas de las cuales están adaptadas para sectores específicos de la economía, regiones climáticas y condiciones que afectan a un área en específico (Wilhite \& Glantz, 1985; Correia, Santos, \& Rodrigues, 1991; Tate \& Gustard, 2000), pero ninguna es universalmente aceptada debido a que se trata de un fenómeno relativo cuyas características varían de un lugar a otro. Hace 36 años, Wilhite y Glantz 
Tecnología y

Ciencias $\approx$ Agua
2022, Instituto Mexicano de Tecnología del Agua Open Access bajo la licencia CC BY-NC-SA 4.0 (https://creativecommons.org/licenses/by-nc$\mathrm{sa} / 4.0 /)$

(1985) detectaron más de 150 definiciones de sequía publicadas en la literatura, y las clasificaron en cuatro grupos según la disciplina científica desde la que es analizado el fenómeno y sus impactos: sequía meteorológica, sequía agrícola, sequía hidrológica y sequía socioeconómica. Esta clasificación sigue vigente y es ampliamente utilizada en artículos científicos especializados en el tema (p. ej., Bootsma, Boisvert, \& Baier, 1996; Barakat \& Handoufe, 1998; Wilhite, 2000; Valiente, 2001; Bergaoui \& Alouini, 2001; Boken, 2005; Mishra \& Singh, 2010). Los primeros tres enfoques o tipos de sequía (meteorológica, agrícola e hidrológica) tratan formas de medir la sequía como un fenómeno físico; el último enfoque (sequía socioeconómica) aborda la sequía en términos de oferta y demanda, rastreando los efectos del déficit de agua a medida que se propaga a través de los sistemas socioeconómicos. La sequía meteorológica se define por lo general en función del grado de disminución de la lluvia en comparación con alguna cantidad "normal" o promedio, y la duración del periodo seco. La sequía agrícola vincula varias características de la sequía meteorológica (o hidrológica) con los impactos agrícolas, centrándose en la escasez de precipitaciones, las diferencias entre la evapotranspiración real y potencial, y los déficits hídricos del suelo. La sequía hidrológica se asocia con los efectos de los periodos de precipitación deficitarios en el suministro de agua superficial o subterránea. La sequía socioeconómica difiere de los tipos de sequía antes mencionados, porque su ocurrencia depende de los procesos de oferta y demanda de agua en un tiempo y espacio determinados. En la Figura 2 se muestra la secuencia de evolución de los diversos tipos de sequía descritos. 
Teccnología y

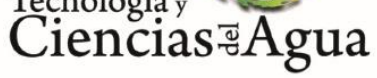

2022, Instituto Mexicano de Tecnología del Agua

Open Access bajo la licencia CC BY-NC-SA 4.0 (https://creativecommons.org/licenses/by-nc$\mathrm{sa} / 4.0 /)$

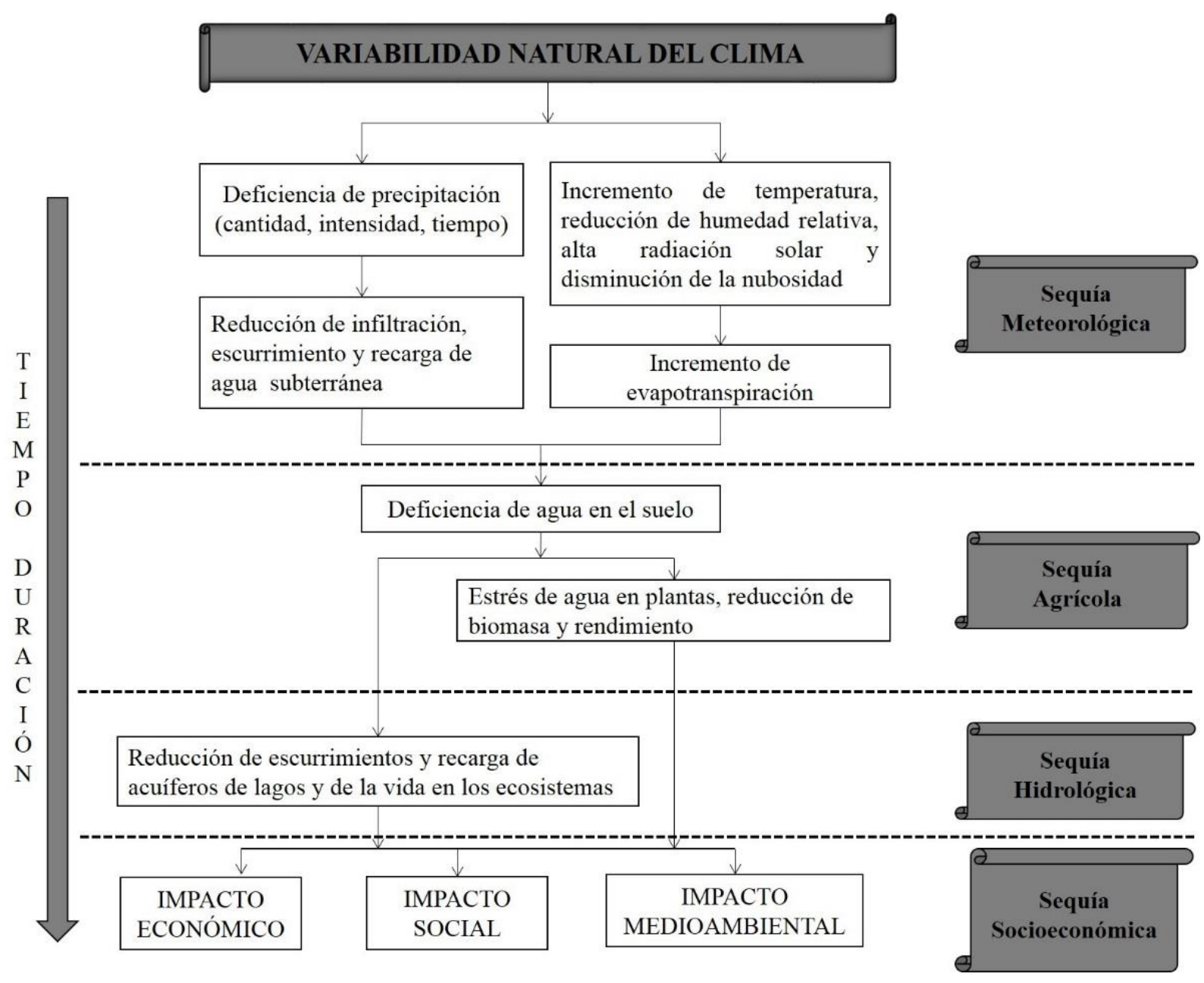

Figura 2. Secuencia de evolución de los diversos tipos de sequía.

Fuente: modificada de NDMC (1995).

\section{Parámetros de la sequía}


Tecnología y

Ciencias $\stackrel{\unlhd}{\unlhd}$ gua
2022, Instituto Mexicano de Tecnología del Agua

Open Access bajo la licencia CC BY-NC-SA 4.0 (https://creativecommons.org/licenses/by-nc$\mathrm{sa} / 4.0 /)$

Las definiciones operativas de los diversos tipos de sequía necesitan ser trasladadas a un formato numérico (parámetros) para poder precisar las características de los eventos secos (Valiente, 2001). Desde los puntos de vista meteorológico e hidrológico, los parámetros básicos de la sequía son (Burton, Kates, \& White, 1978; Dracup, Lee, \& Paulson, 1980): la magnitud, que es el déficit medio de precipitación o caudal durante el periodo de duración del evento seco; la severidad, que es el déficit acumulado de caudal o precipitación para la duración del periodo seco; la duración, que es el tiempo (número total de días, meses o años consecutivos) durante el cual la precipitación o el caudal totales registrados son inferiores a la precipitación, o el caudal medio de ese mismo periodo. Los parámetros anteriores están en función, entre otros factores, del llamado nivel de truncamiento $\left(X_{0}\right)$, referencia a partir de la cual los valores menores representan una deficiencia y probablemente una sequía, medida en términos de la cantidad de lluvia o escurrimiento (Velasco et al., 2005), como se muestra en la Figura 3. 
Tecnología y

Ciencias $\stackrel{\unlhd}{\unlhd}$ gua
2022, Instituto Mexicano de Tecnología del Agua

Open Access bajo la licencia CC BY-NC-SA 4.0 (https://creativecommons.org/licenses/by-nc$\mathrm{sa} / 4.0 /)$

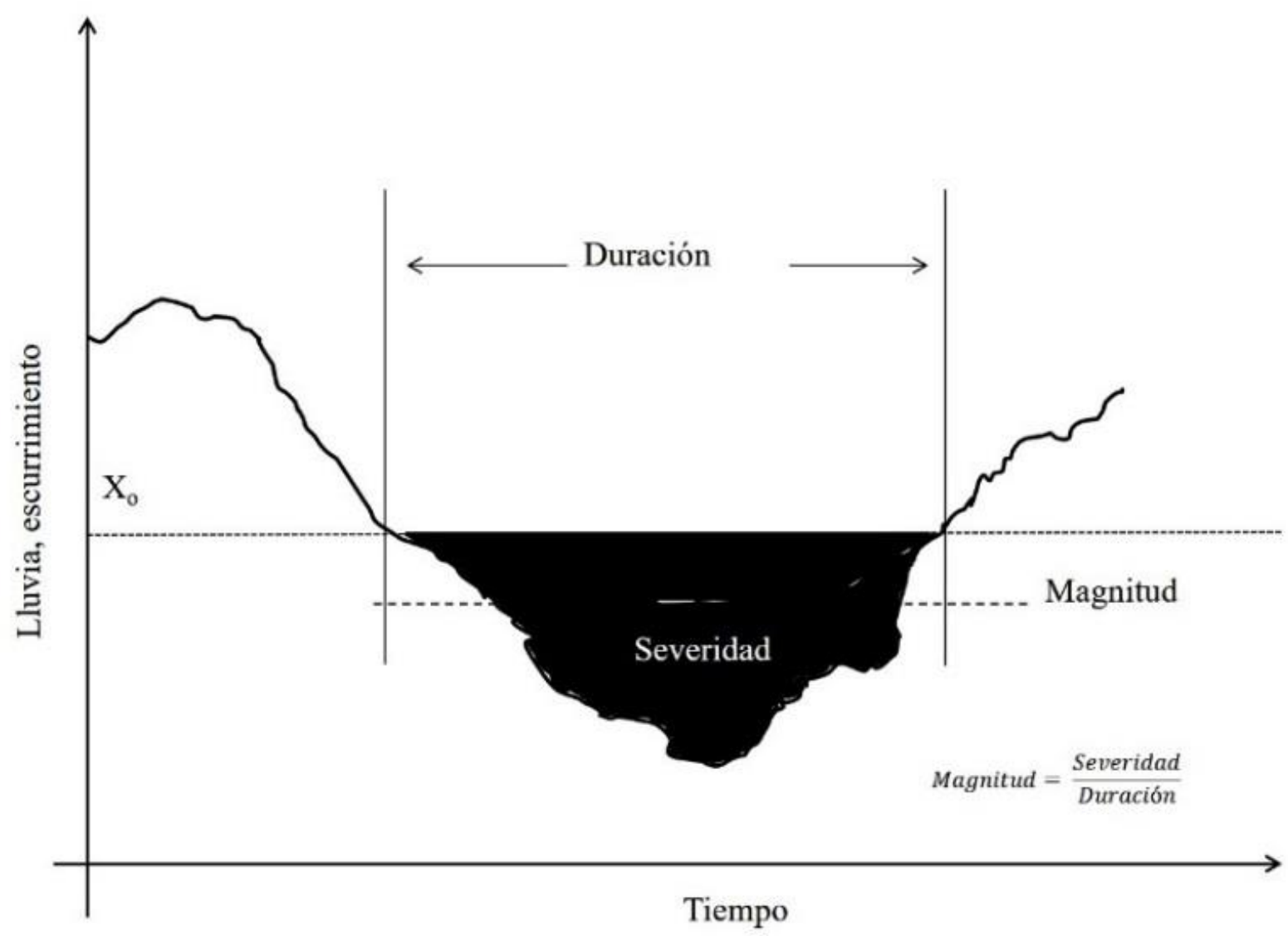

Figura 3. Parámetros básicos para caracterizar la sequía desde las perspectivas meteorológica e hidrológica. Fuente: adaptada de Velasco et al. (2005).

Cuando se analiza la sequía desde los puntos de vista agrícola y socioeconómico es difícil determinar sus características sólo a partir de los parámetros descritos anteriormente. Por lo anterior, para cada tipo de sequía se han creado y utilizado una gran diversidad de métodos y modelos de evaluación basados en índices e indicadores, tal como se describe en el siguiente apartado. 
Teccnología y

Ciencias $₫$ Agua
2022, Instituto Mexicano de Tecnología del Agua

Open Access bajo la licencia CC BY-NC-SA 4.0 (https://creativecommons.org/licenses/by-nc$\mathrm{sa} / 4.0 /)$

\section{Métodos de evaluación de la sequía}

Actualmente existe una amplia variedad de indicadores e índices para caracterizar la sequía principalmente desde las perspectivas meteorológica, agrícola e hidrológica, cada uno de los cuales tiene ventajas y desventajas que limitan o favorecen su aplicación en un ámbito determinado (Byun \& Wilhite, 1999; Heim, 2002; Hayes, Svoboda, Wall, \& Widhalm, 2011). Los indicadores son variables o parámetros utilizados para describir las condiciones de las sequías, por ejemplo: precipitación, temperatura, caudales fluviales, niveles de las aguas subterráneas y de los embalses, humedad del suelo, etcétera; y los índices suelen ser representaciones numéricas informatizadas de la gravedad de las sequías, determinadas mediante datos climáticos o hidrometeorológicos, entre los que se incluyen los indicadores mencionados, y tienen por objeto analizar el estado cualitativo de las sequías en el entorno en un periodo de tiempo determinado. De la misma forma que no hay una definición única de sequía, no existe ningún índice o indicador que pueda atribuirse y ser aplicado a todos los tipos de sequía, regímenes climáticos y sectores afectados por las sequías (OMM \& GWP, 2016).

Desde el punto de vista meteorológico, los indicadores de la sequía están asociados con variables climatológicas como 
Tecnología y

Ciencias $₫$ Agua
2022, Instituto Mexicano de Tecnología del Agua Open Access bajo la licencia CC BY-NC-SA 4.0 (https://creativecommons.org/licenses/by-nc$\mathrm{sa} / 4.0 /)$

precipitación, temperatura y evapotranspiración (Wilhite, 2005). Algunos de los índices más comunes para caracterizar la sequía meteorológica incluyen los deciles; el Índice de Anomalía Pluviométrica (RAI); el Índice Estandarizado de Precipitación (SPI); el Índice de Sequía Efectiva (EDI); y el Índice Estandarizado de Precipitación y Evapotranspiración (SPEI). Desde la perspectiva agrícola, los indicadores de la sequía consideran datos de humedad del suelo para detectar situaciones de sequía en los cultivos, y se enfocan en las anomalías de los valores de humedad del suelo con respecto a la estación y ubicación (Wanders, Van-Lanen, \& VanLoon, 2010), por ejemplo, el Índice de Severidad de Sequía de Palmer (PDSI); el Índice de Anomalía de la Humedad del Suelo (SMA); el Índice del Déficit de Evapotranspiración (ETDI); y el Índice del Déficit de Humedad del Suelo (SMDI). Asimismo, existen diversos índices basados en información satelital (teledetección) que identifican el estado de salud de la vegetación, y son útiles para identificar y caracterizar la sequía en la agricultura; algunos de estos índices incluyen el Índice Diferencial Normalizado de Vegetación (NDVI) y el Índice de Salud de la Vegetación (VHI). Por último, desde el punto de vista hidrológico, los indicadores de sequía se refieren a variables del sistema hídrico, como los niveles de las aguas subterráneas, los caudales de los ríos y el almacenamiento de los embalses, principalmente (Wanders et al., 2010). Algunos índices derivados de estos indicadores incluyen el Índice de Sequía Hidrológica de Palmer (PHDI); el Índice de Abastecimiento de las Aguas Superficiales (SWSI); el Índice 
Tecnología y

Ciencias Agua
2022, Instituto Mexicano de Tecnología del Agua Open Access bajo la licencia CC BY-NC-SA 4.0 (https://creativecommons.org/licenses/by-nc$\mathrm{sa} / 4.0 /)$

Normalizado del Nivel de Agua (SWI); el Índice Normalizado de los Caudales Fluviales (SSFI); el Índice de Sequía de los Caudales Fluviales (SDI), y el Índice Normalizado del Suministro de Embalses (SRSI). En la Tabla 1 se presentan los orígenes, aplicaciones, ventajas y desventajas de cada uno de los índices antes mencionados. Para una descripción más detallada de cada uno de ellos y recomendaciones específicas sobre su uso se sugiere revisar el Manual de indicadores e índices de sequía (OMM \& GWP, 2016). En dicho manual se menciona, por ejemplo, que en 2009 la OMM recomendó a los países que utilizaran el SPI como principal índice para vigilar y dar seguimiento a las condiciones de sequía meteorológica.

Tabla 1. Características de los índices de sequía comúnmente utilizados.

\begin{tabular}{|c|c|c|c|c|c|}
\hline $\begin{array}{c}\text { Tipo } \\
\text { de } \\
\text { sequía }\end{array}$ & Índice & $\begin{array}{c}\text { Variables } \\
\text { de } \\
\text { entrada* }\end{array}$ & Origen y aplicaciones & Ventajas & Desventajas \\
\hline 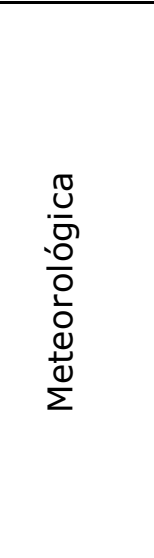 & Deciles & $\mathrm{P}$ & $\begin{array}{l}\text { Creado por Gibbs et al. } \\
\text { (1967) en la Oficina de } \\
\text { Meteorología de Australia. } \\
\text { Se puede utilizar donde se } \\
\text { tenga el periodo íntegro de } \\
\text { registros de precipitación de } \\
\text { un lugar (de preferencia } \\
\text { más de } 30 \text { años), a partir } \\
\text { del cual se clasifica la }\end{array}$ & $\begin{array}{l}\text { Puesto que analiza una } \\
\text { sola variable, es un } \\
\text { método flexible y útil en } \\
\text { situaciones de humedad } \\
\text { y sequía }\end{array}$ & $\begin{array}{l}\text { No se tienen en cuenta } \\
\text { los efectos de la } \\
\text { temperatura ni de otras } \\
\text { variables durante el } \\
\text { desarrollo de la sequía }\end{array}$ \\
\hline
\end{tabular}


Tecnología y

Ciencias $\stackrel{\Xi}{\Im}$ Aua
2022, Instituto Mexicano de Tecnología del Agua

Open Access bajo la licencia CC BY-NC-SA 4.0

(https://creativecommons.org/licenses/by-nc$\mathrm{sa} / 4.0 /)$

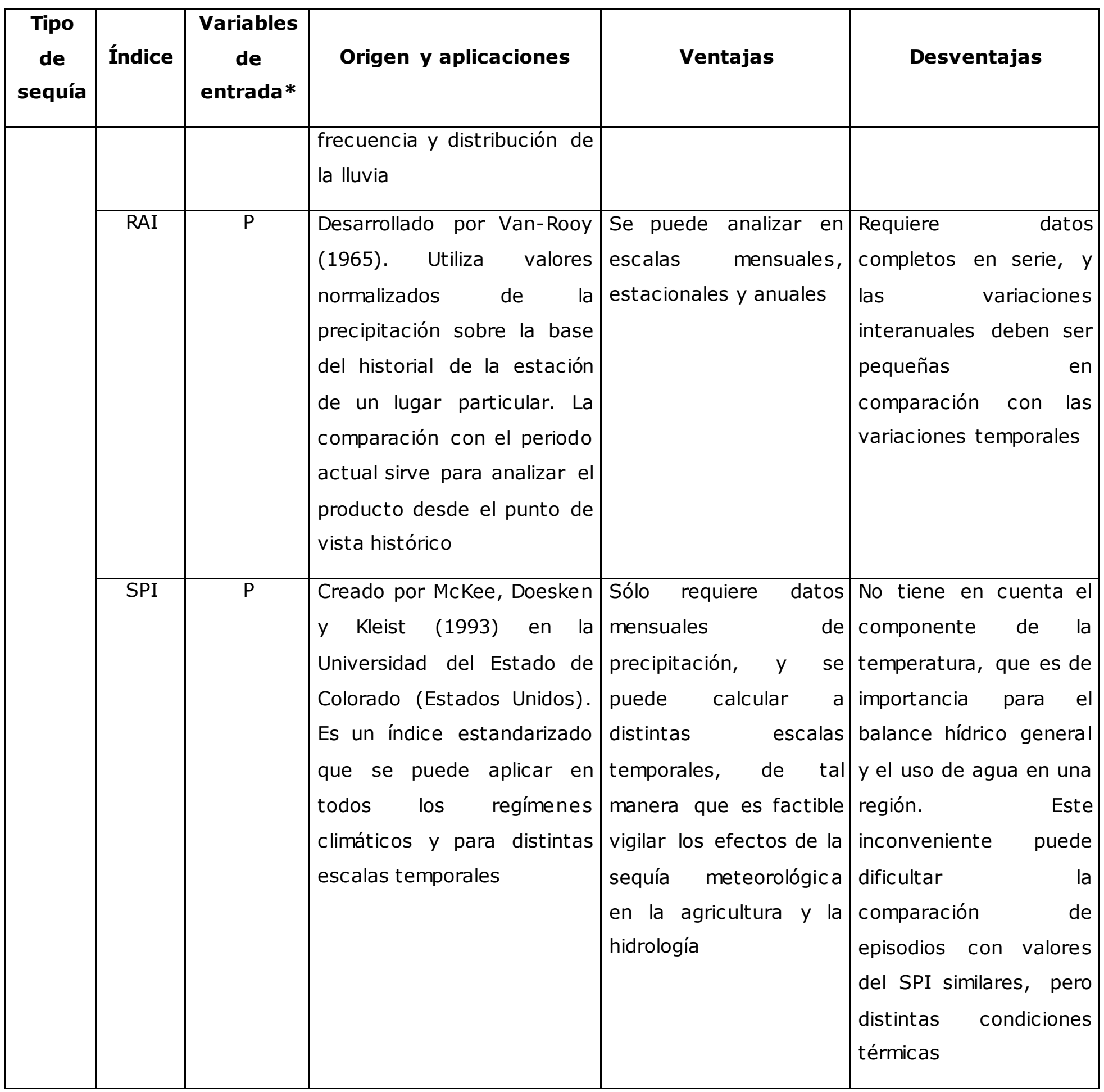


Tecnología y

Ciencias $\stackrel{\Xi}{\Im}$ Aua
2022, Instituto Mexicano de Tecnología del Agua

Open Access bajo la licencia CC BY-NC-SA 4.0 (https://creativecommons.org/licenses/by-nc$\mathrm{sa} / 4.0 /)$

\begin{tabular}{|c|c|c|c|c|c|}
\hline $\begin{array}{c}\text { Tipo } \\
\text { de } \\
\text { sequía }\end{array}$ & Índice & $\begin{array}{c}\text { Variables } \\
\text { de } \\
\text { entrada* }\end{array}$ & Origen y aplicaciones & Ventajas & Desventajas \\
\hline & EDI & $\bar{P}$ & $\begin{array}{l}\text { Desarrollado por Byun \& } \\
\text { Wilhite (1999) en el Centro } \\
\text { Nacional de Mitigación de la } \\
\text { Sequía de Estados Unidos. } \\
\text { Sirve para detectar el inicio } \\
\text { y final de periodos de déficit } \\
\text { hídrico. Se puede calcular } \\
\text { en cualquier lugar del } \\
\text { mundo en que se disponga } \\
\text { de registros diarios de } \\
\text { precipitación }\end{array}$ & $\begin{array}{l}\text { Es aplicable a todos los } \\
\text { regímenes climáticos y } \\
\text { los productos son } \\
\text { comparables porque } \\
\text { están normalizados }\end{array}$ & $\begin{array}{l}\text { El uso de datos diarios } \\
\text { de precipitación puede } \\
\text { dificultar el empleo del } \\
\text { índice en contextos } \\
\text { operativos, pues quizá } \\
\text { no sea posible } \\
\text { actualizar a diario los } \\
\text { datos de entrada }\end{array}$ \\
\hline & SPEI & $\mathrm{P}, \mathrm{T}$ & 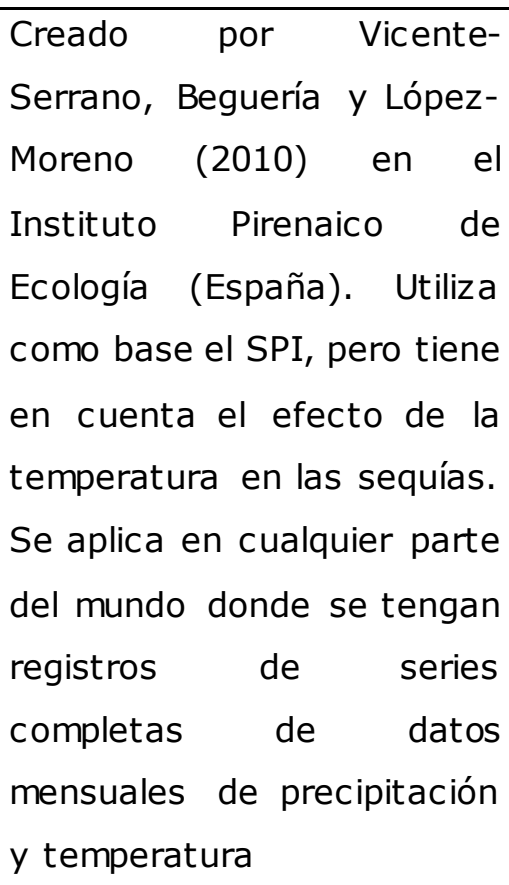 & $\begin{array}{l}\text { Dado que utiliza datos } \\
\text { de temperatura, es } \\
\text { idóneo para observar el } \\
\text { efecto del cambio } \\
\text { climático en los } \\
\text { productos de los } \\
\text { modelos de acuerdo con } \\
\text { distintos supuestos } \\
\text { futuros }\end{array}$ & $\begin{array}{l}\text { Es necesario disponer } \\
\text { de datos mensuales } \\
\text { suficientes de } \\
\text { precipitación } \\
\text { temperatura. } \\
\text { tratarse de un índice } \\
\text { mensual, es posible que } \\
\text { no se detecten } \\
\text { inmediatamente las } \\
\text { situaciones de sequía } \\
\text { que se desarrollan con } \\
\text { rapidez }\end{array}$ \\
\hline - & PDSI & $\mathrm{P}, \mathrm{T}, \mathrm{CAD}$ & $\begin{array}{llll}\text { Desarrollado } & \text { por } & \text { Palmer } \\
(1968) \text { en } & \text { la } & \text { Oficina }\end{array}$ & $\begin{array}{l}\text { Es bastante fiable para } \\
\text { detectar sequías gracias }\end{array}$ & $\begin{array}{l}\text { La necesidad } \text { de } \\
\text { disponer de datos }\end{array}$ \\
\hline
\end{tabular}


Tecnología y

Ciencias $\stackrel{\unlhd}{\unlhd}$ gua
2022, Instituto Mexicano de Tecnología del Agua

Open Access bajo la licencia CC BY-NC-SA 4.0

(https://creativecommons.org/licenses/by-nc$\mathrm{sa} / 4.0 /)$

\begin{tabular}{|c|c|c|c|c|c|}
\hline $\begin{array}{c}\text { Tipo } \\
\text { de } \\
\text { sequía }\end{array}$ & Índice & $\begin{array}{c}\text { Variables } \\
\text { de } \\
\text { entrada* }\end{array}$ & Origen y aplicaciones & Ventajas & Desventajas \\
\hline & & & $\begin{array}{l}\text { Meteorológica de Estados } \\
\text { Unidos para evaluar las } \\
\text { sequías que afectan a la } \\
\text { agricultura en las regiones } \\
\text { productoras de cultivos de } \\
\text { ese país. Ha sido aplicado y } \\
\text { es muy popular en distintas } \\
\text { partes del mundo, pues } \\
\text { durante muchos años fue el } \\
\text { único índice operativo de } \\
\text { sequía }\end{array}$ & $\begin{array}{l}\text { a la utilización de datos } \\
\text { del suelo y de una } \\
\text { metodología del balance } \\
\text { hídrico total }\end{array}$ & $\begin{array}{l}\text { completos en serie } \\
\text { puede causar } \\
\text { problemas. Tiene una } \\
\text { escala temporal de } \\
\text { nueve meses, } \\
\text { aproximadamente, lo } \\
\text { que deriva en un } \\
\text { desfase al detectar } \\
\text { condiciones de sequía } \\
\text { sobre la base del } \\
\text { componente de } \\
\text { humedad del suelo en } \\
\text { los cálculos }\end{array}$ \\
\hline & SMA & $\mathrm{P}, \mathrm{T}, \mathrm{CAD}$ & $\begin{array}{l}\text { Creado por Bergman, Sabol, } \\
\text { y Miskus (1988) en el } \\
\text { Servicio Meteorológico } \\
\text { Nacional de EEUU, como } \\
\text { método para evaluar las } \\
\text { condiciones mundiales de } \\
\text { sequía. Se puede usar } \\
\text { donde se tengan datos } \\
\text { semanales o mensuales de } \\
\text { temperatura y precipitación, } \\
\text { así como valores de la } \\
\text { capacidad de retención de } \\
\text { humedad del suelo }\end{array}$ & $\begin{array}{l}\text { Al tener en cuenta los } \\
\text { efectos de la } \\
\text { temperatura y la } \\
\text { precipitación en la } \\
\text { humedad del suelo, } \\
\text { comprende los aspectos } \\
\text { principales del balance } \\
\text { hídrico }\end{array}$ & $\begin{array}{l}\text { Resulta difícil de } \\
\text { calcular debido a la } \\
\text { necesidad de datos para } \\
\text { distintas capas del } \\
\text { suelo. Las estimaciones } \\
\text { de } \\
\text { evapotranspiración } \\
\text { potencial pueden variar } \\
\text { de forma considerable } \\
\text { en función de la región }\end{array}$ \\
\hline
\end{tabular}


Tecnología y

Ciencias $\stackrel{\Xi}{\unlhd}$ Aua
2022, Instituto Mexicano de Tecnología del Agua

Open Access bajo la licencia CC BY-NC-SA 4.0

(https://creativecommons.org/licenses/by-nc$\mathrm{sa} / 4.0 /)$

\begin{tabular}{|c|c|c|c|c|c|}
\hline $\begin{array}{l}\text { Tipo } \\
\text { de } \\
\text { sequía }\end{array}$ & Índice & $\begin{array}{l}\text { Variables } \\
\text { de } \\
\text { entrada* }\end{array}$ & Origen y aplicaciones & Ventajas & Desventajas \\
\hline & ETDI & Mod & 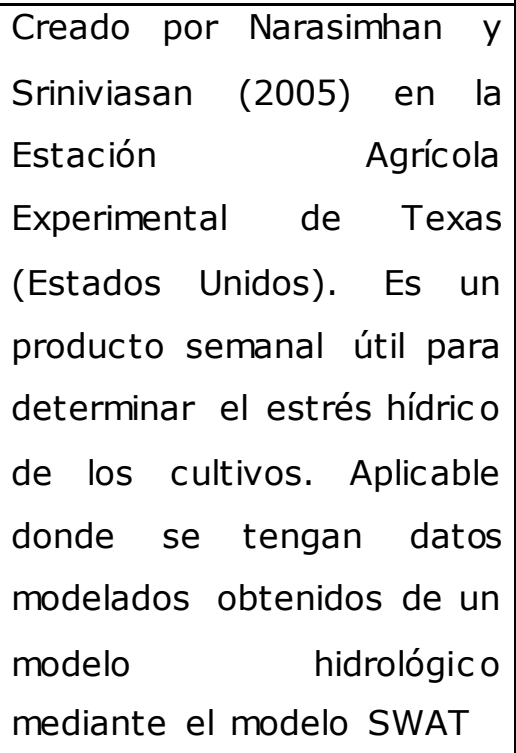 & $\mid \begin{array}{lrr}\text { Analiza } & \text { tanto } & \text { la } \\
\text { evapotranspiración } & \text { real } \\
\text { como } & \text { potencial } & \text { y } \\
\text { permite } & \text { detectar } \\
\text { periodos } & \text { húmedos } & \text { y } \\
\text { secos } & & \end{array}$ & $\begin{array}{l}\text { La variabilidad espacial } \\
\text { del índice aumenta en } \\
\text { los meses de verano } \\
\text { durante el periodo de } \\
\text { mayor } \\
\text { evapotranspiración y de } \\
\text { precipitación muy } \\
\text { variable }\end{array}$ \\
\hline & SMDI & Mod & 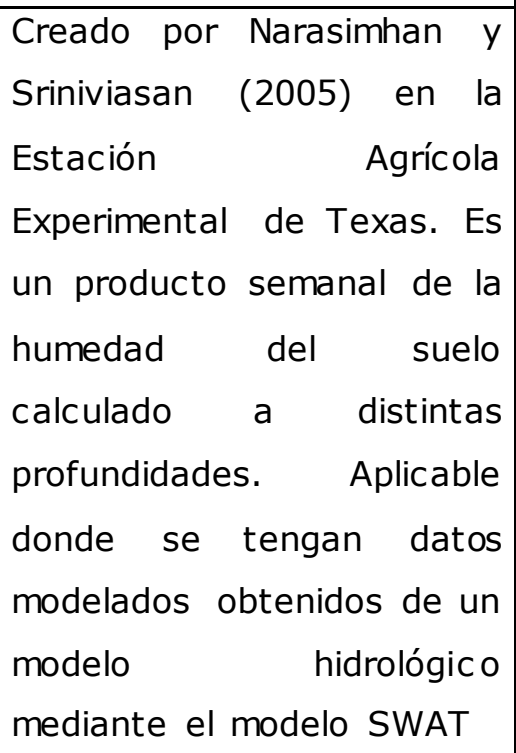 & $\begin{array}{l}\text { Tiene en cuenta el perfil } \\
\text { completo del suelo y } \\
\text { distintas profundidades, } \\
\text { por lo que se puede } \\
\text { adaptar a diversos tipos } \\
\text { de cultivo }\end{array}$ & $\begin{array}{l}\text { La información } \\
\text { necesaria para calcular } \\
\text { el índice se basa en el } \\
\text { producto del modelo } \\
\text { SWAT (instrumento de } \\
\text { evaluación del suelo y el } \\
\text { agua). Hay problemas } \\
\text { de autocorrelación } \\
\text { cuando se utilizan todas } \\
\text { las profundidades }\end{array}$ \\
\hline & NDVI & Sat & $\begin{array}{l}\text { Desarrollado por Tarpley, } \\
\text { Schneider y Money (1984), } \\
\text { y Kogan (1995) en la }\end{array}$ & $\begin{array}{l}\text { Innovador, dado que } \\
\text { utiliza datos satelitales } \\
\text { para vigilar la salud de }\end{array}$ & $\begin{array}{l}\text { El procesamiento de } \\
\text { datos es esencial para } \\
\text { el índice, fase para la }\end{array}$ \\
\hline
\end{tabular}


Teccnología y

Ciencias $\stackrel{\Xi}{\Im}$ Aua
2022, Instituto Mexicano de Tecnología del Agua

Open Access bajo la licencia CC BY-NC-SA 4.0

(https://creativecommons.org/licenses/by-nc$\mathrm{sa} / 4.0 /)$

\begin{tabular}{|c|c|c|c|c|c|}
\hline $\begin{array}{l}\text { Tipo } \\
\text { de } \\
\text { sequía }\end{array}$ & Índice & $\begin{array}{l}\text { Variables } \\
\text { de } \\
\text { entrada* }\end{array}$ & Origen y aplicaciones & Ventajas & Desventajas \\
\hline & & & $\begin{array}{l}\text { Administración Nacional } \\
\text { Oceánica y Atmosférica } \\
\text { (NOAA) de Estados Unidos. } \\
\text { Utiliza datos obtenidos del } \\
\text { satélite AVHRR de la NOAA. } \\
\text { Aplicable para vigilar las } \\
\text { sequías agrícolas en todo el } \\
\text { mundo }\end{array}$ & $\begin{array}{l}\text { la vegetación en } \\
\text { relación con los } \\
\text { episodios de sequía. } \\
\text { Resolución muy alta y } \\
\text { excelente cobertura } \\
\text { espacial }\end{array}$ & $\begin{array}{l}\text { cual es necesario contar } \\
\text { con un sistema sólido. } \\
\text { El historial de los datos } \\
\text { satelitales no es muy } \\
\text { amplio }\end{array}$ \\
\hline & VHI & Sat & $\begin{array}{l}\text { Creado por Kogan (1990) en } \\
\text { la NOAA. Es un derivado del } \\
\text { índice NDVI que utiliza datos } \\
\text { del satélite AVHRR. Se usa } \\
\text { para detectar y vigilar las } \\
\text { sequías que afectan la } \\
\text { agricultura en todo el } \\
\text { mundo }\end{array}$ & $\begin{array}{l}\text { Tiene cobertura en todo } \\
\text { el mundo y alta } \\
\text { resolución }\end{array}$ & $\begin{array}{l}\text { El periodo de registro de } \\
\text { los datos satelitales es } \\
\text { corto }\end{array}$ \\
\hline $\begin{array}{l}\frac{0}{0} \\
\frac{0}{0} \\
\frac{0}{\frac{0}{x}} \\
\frac{1}{1}\end{array}$ & PHDI & $P, T, C A D$ & $\begin{array}{l}\text { Parte del conjunto de } \\
\text { índices creados por Palmer } \\
\text { (1965) en la Oficina } \\
\text { Meteorológica de Estados } \\
\text { Unidos. Se basa en el PDSI } \\
\text { original y modificado para } \\
\text { tener en cuenta la sequía de } \\
\text { larga duración que influirá } \\
\text { en las componentes } \\
\text { hidrológicas }\end{array}$ & $\begin{array}{l}\text { Su método de balance } \\
\text { hídrico permite analizar } \\
\text { el sistema hídrico en su } \\
\text { integridad }\end{array}$ & $\begin{array}{l}\text { En los cálculos no se } \\
\text { tiene en cuenta el } \\
\text { influjo humano, como } \\
\text { las decisiones de } \\
\text { gestión y el riego }\end{array}$ \\
\hline
\end{tabular}


Tecnología y

Ciencias $\stackrel{\unlhd}{\unlhd}$ gua
2022, Instituto Mexicano de Tecnología del Agua

Open Access bajo la licencia CC BY-NC-SA 4.0

(https://creativecommons.org/licenses/by-nc$\mathrm{sa} / 4.0 /)$

\begin{tabular}{|c|c|c|c|c|c|}
\hline $\begin{array}{c}\text { Tipo } \\
\text { de } \\
\text { sequía }\end{array}$ & Índice & $\begin{array}{c}\text { Variables } \\
\text { de } \\
\text { entrada* }\end{array}$ & Origen y aplicaciones & Ventajas & Desventajas \\
\hline & SWSI & $\begin{array}{c}\mathrm{P}, \mathrm{CF}, \mathrm{EM}, \\
\mathrm{MN}\end{array}$ & $\begin{array}{l}\text { Creado por Shafer y } \\
\text { Dezman (1982) para } \\
\text { solucionar directamente } \\
\text { varias de las limitaciones } \\
\text { detectadas en el PDSI. } \\
\text { Incorpora datos de } \\
\text { abastecimiento de agua } \\
\text { (fusión de la nieve, } \\
\text { escorrentía, embalses) y se } \\
\text { calcula para una cuenca }\end{array}$ & $\begin{array}{l}\text { Al tener en cuenta todos } \\
\text { los recursos hídricos de } \\
\text { una cuenca proporciona } \\
\text { un buen indicio de la } \\
\text { salud hidrológica } \\
\text { general de una cuenca o } \\
\text { región concreta }\end{array}$ & $\begin{array}{l}\text { Al cambiar las fuentes } \\
\text { de datos se tiene que } \\
\text { recalcular el índice } \\
\text { completo, lo que } \\
\text { dificulta la elaboración } \\
\text { de una serie cronológica } \\
\text { homogénea. Puesto que } \\
\text { los cálculos pueden } \\
\text { variar entre cuencas es } \\
\text { complicado comparar } \\
\text { cuencas o regiones } \\
\text { homogéneas }\end{array}$ \\
\hline & SWI & AS & $\begin{array}{l}\text { Creado por Bhuiyan (2004) } \\
\text { en el Instituto de Tecnología } \\
\text { de India como instrumento } \\
\text { para evaluar los déficits de } \\
\text { recarga del agua } \\
\text { subterránea. Se utiliza } \\
\text { donde se tengan datos de } \\
\text { los niveles de los pozos }\end{array}$ & $\begin{array}{l}\text { Analiza el efecto de la } \\
\text { sequía en el agua } \\
\text { subterránea, que es un } \\
\text { componente esencial } \\
\text { del abastecimiento de } \\
\text { agua para usos } \\
\text { agrícolas y municipales }\end{array}$ & $\begin{array}{l}\text { Dado que no toma en } \\
\text { cuenta las aguas } \\
\text { superficiales, es posible } \\
\text { que la interpolación } \\
\text { entre puntos (datos de } \\
\text { los pozos de agua } \\
\text { subterránea) no sea } \\
\text { representativa de la } \\
\text { región o el régimen } \\
\text { climático }\end{array}$ \\
\hline & SSFI & $\mathrm{CF}$ & $\begin{array}{l}\text { Creado originalmente por } \\
\text { Modarres (2007). Utiliza } \\
\text { valores mensuales de los } \\
\text { caudales fluviales y los } \\
\text { métodos de normalización }\end{array}$ & $\begin{array}{l}\text { Examina el efecto de la } \\
\text { sequía en los caudales } \\
\text { fluviales, componente } \\
\text { esencial para el } \\
\text { abastecimiento de agua }\end{array}$ & $\begin{array}{l}\text { Sólo representa los } \\
\text { caudales fluviales en el } \\
\text { contexto del } \\
\text { seguimiento de sequías }\end{array}$ \\
\hline
\end{tabular}


Tecnología y

Ciencias $\stackrel{\Xi}{\Im}$ Aua
2022, Instituto Mexicano de Tecnología del Agua

Open Access bajo la licencia CC BY-NC-SA 4.0

(https://creativecommons.org/licenses/by-nc$\mathrm{sa} / 4.0 /)$

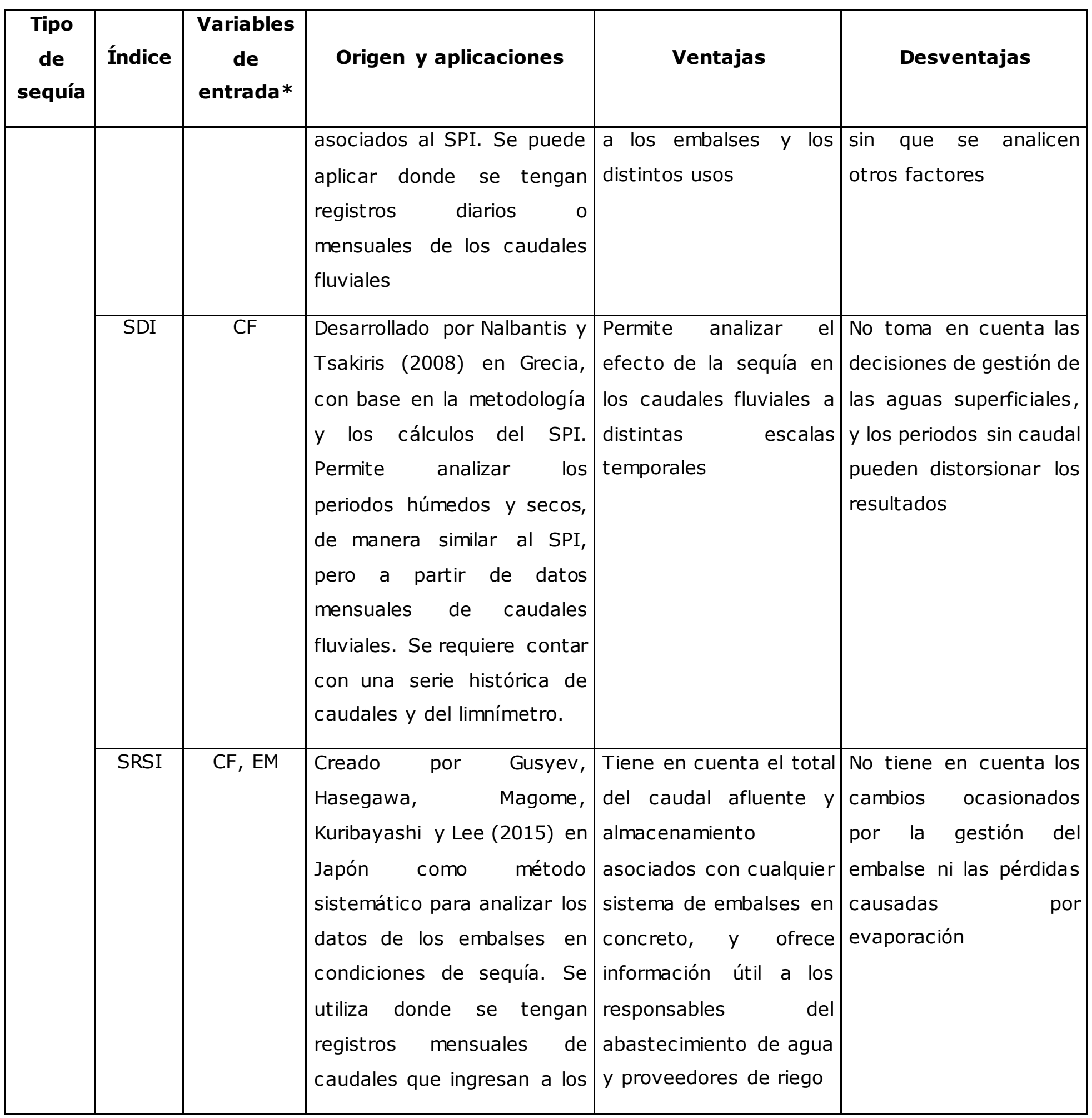


Tecnología y

Ciencias $\stackrel{\Xi}{\Im}$ Agua
2022, Instituto Mexicano de Tecnología del Agua

Open Access bajo la licencia CC BY-NC-SA 4.0 (https://creativecommons.org/licenses/by-nc$\mathrm{sa} / 4.0 /)$

\begin{tabular}{|c|c|c|c|c|c|}
\hline $\begin{array}{c}\text { Tipo } \\
\text { de } \\
\text { sequía }\end{array}$ & Índice & $\begin{array}{c}\text { Variables } \\
\text { de } \\
\text { entrada* }\end{array}$ & Origen y aplicaciones & Ventajas & Desventajas \\
\hline & & $\begin{array}{c}\text { embalses y volúmenes } \\
\text { medios de almacenamiento }\end{array}$ & & \\
\hline
\end{tabular}

*Leyenda de las variables: $A S=$ aguas subterráneas; $C A D=$ contenido de agua disponible; $C F=$ caudales fluviales; $E M=$ embalse; $M N=$ manto de nieve; $M o d=$ modelado; $\mathrm{P}=$ precipitación; Sat $=$ información satelital; $\mathrm{T}=$ temperatura. Fuente: elaboración propia a partir de OMM y GWP (2016).

En años recientes, debido a la gran relevancia y contribución que han tenido los métodos basados en inteligencia artificial en la modelización y predicción de los procesos hidrológicos y climáticos (Ardabili, Mosavi, Dehghani, \& Varkonyi-Koczy, 2019), las técnicas de aprendizaje automático (mejor conocidas como learning machine) han sido utilizadas en combinación con algunos de los índices de sequía descritos arriba para la evaluación, monitoreo y pronóstico de la sequía. Por ejemplo, Rhee e Im (2017) desarrollaron un modelo de pronóstico de sequía de alta resolución en Corea del Sur usando la técnica de los árboles extremadamente aleatorios y los índices SPI y SPEI; por su parte, Deo y Sahin (2015) aplicaron el algoritmo del aprendizaje automático extremo para la predicción del índice EDI en Australia; Park, Im, Jang y Rhee (2015) utilizaron tres enfoques de aprendizaje automático (bosque aleatorio, árboles de regresión potenciados y cubista), en conjunto con los índices SPI y NDVI, para realizar la evaluación y seguimiento de la sequía meteorológica y agrícola en Estados Unidos; Feng, 
Tecnología y

Ciencias $\stackrel{\unlhd}{\unlhd}$ gua
2022, Instituto Mexicano de Tecnología del Agua

Open Access bajo la licencia CC BY-NC-SA 4.0 (https://creativecommons.org/licenses/by-nc$\mathrm{sa} / 4.0 /)$

Wang, Liu y Yu (2019) adoptaron tres métodos avanzados de aprendizaje automático (bosque aleatorio con corrección de sesgo, máquina de vectores de soporte y redes neuronales), en combinación con el índice SPEI para mejorar las predicciones de la sequía agrícola en el sureste de Australia; y Zhang, Chen, Xu y Ou (2019) utilizaron el método de redes neuronales artificiales y el índice SPEI para predecir sequías meteorológicas en la provincia de Shaanxi, China, entre muchas otras investigaciones.

Sin embargo, es importante mencionar que a pesar de la gran utilidad de los índices de sequía para realizar el monitoreo, evaluación y pronóstico del fenómeno (desde las perspectivas meteorológica, agrícola e hidrológica), ninguno de ellos es válido para evaluar el impacto socioeconómico de las sequías. La evaluación de este impacto es considerada por algunos expertos como un problema no resuelto $y$, hasta cierto punto, como una misión imposible (Marcos, 2001). Ello se debe sobre todo a que el fenómeno de la sequía provoca una compleja e intrincada red de efectos económicos, sociales y ambientales, que se acumulan de manera gradual y que pueden permanecer incluso años después de la terminación del evento (Ortega-Gaucin, 2012a); además, la información generada en torno al fenómeno por lo general es poca y dispersa, lo cual obstaculiza la realización de cálculos exactos, confiables y oportunos de sus efectos y de la gravedad de los mismos y, en última instancia, impide o limita en gran manera la formulación de planes de contingencia por la mayoría de los gobiernos de los países afectados (Wilhite, 2000). Entonces, por la 
Tecnología y

Ciencias $₫$ Agua
2022, Instituto Mexicano de Tecnología del Agua

Open Access bajo la licencia CC BY-NC-SA 4.0 (https://creativecommons.org/licenses/by-nc$\mathrm{sa} / 4.0 /)$

naturaleza misma del fenómeno, no existe una respuesta única y definitiva a la pregunta ¿Cuál es el impacto socioeconómico de una sequía? Los impactos totales y sectoriales dependerán de la duración y extensión territorial del fenómeno; de la cuantía de la reducción en la disponibilidad de agua (Ortega-Gaucin, 2012b); así como de las condiciones económicas tanto estructurales como coyunturales, incluyendo la etapa de desarrollo y los precios de los cultivos afectados (Sisto, Guajardo-Quiroga, \& Aguilar-Barajas, 2011), entre otras variables. Los impactos de la insuficiencia del agua se traducen en menor producción e ingreso, pues los volúmenes disponibles durante el periodo de sequía no alcanzan para satisfacer la demanda de agua en condiciones normales. Así, la evaluación de la sequía en términos económicos se hace principalmente con base en conceptos como: productividad, ingreso, eficiencia, desempleo, etcétera (Sisto et al., 2011). Para el sector agropecuario, los análisis económicos en términos de superficies cosechadas y siniestradas, volumen de la producción, valor de la producción, cabezas de ganado perdidas, entre otros elementos, proporcionan indicadores de impacto de la sequía y reflejan, quizá mejor que en los otros sectores, que el déficit hídrico tiene severos efectos negativos en un ámbito totalmente dependiente del recurso (Velasco, 2002; Ortega-Gaucin, 2012a; Ortega-Gaucin, 2012b).

Sin embargo, para gestionar el riesgo de sequía de manera efectiva es importante comprender los posibles impactos, aunque sea en términos relativos, e identificar quién estará en riesgo y por 
Tecnología y

Ciencias $\stackrel{\unlhd}{\unlhd}$ gua
2022, Instituto Mexicano de Tecnología del Agua

Open Access bajo la licencia CC BY-NC-SA 4.0 (https://creativecommons.org/licenses/by-nc$\mathrm{sa} / 4.0 /)$

qué. Por ello, evaluar el peligro, exposición, vulnerabilidad y riesgo implica en cierto sentido la predicción de la gravedad y el alcance de la amenaza, así como sus posibles efectos en la economía y la sociedad, a la vez que permite a los tomadores de decisiones diseñar medidas para prevenir y mitigar los impactos (OrtegaGaucin \& Velasco, 2015). De ahí la importancia de hacer análisis y evaluaciones de estas variables.

\section{Exposición a la sequía}

EI IPCC (2014) define la exposición como la presencia de personas, propiedades, medios de vida y sistemas que están sujetos a daños y pérdidas potenciales debido al peligro. En los últimos años, la mayor exposición de la población a fenómenos meteorológicos extremos ha resultado en mayor número de desastres. La exposición es un factor que genera vulnerabilidad, de tal forma que si no hay exposición a un fenómeno específico no existe riesgo (Magaña, 2013). En el contexto de una sequía meteorológica y agrícola, por ejemplo, la exposición incluye a los cultivos de temporal, así como a los agricultores y ganaderos que trabajan en este sector, quienes están expuestos a perder su fuente de trabajo, alimentación e ingreso económico (Ortega-Gaucin, De-la-Cruz- 
Tecnología y

Ciencias $\stackrel{\unlhd}{\unlhd}$ gua
2022, Instituto Mexicano de Tecnología del Agua

Open Access bajo la licencia CC BY-NC-SA 4.0 (https://creativecommons.org/licenses/by-nc$\mathrm{sa} / 4.0 /)$

Bartolón, \& Castellano-Bahena, 2018a); en el caso de una sequía hidrológica, incluye a todos los usuarios de aguas superficiales y subterráneas, como son los distritos y unidades de riego, las hidroeléctricas, los usuarios públicos urbanos e industriales, y todas la personas del medio rural que carecen de agua suficiente para desarrollar sus actividades cotidianas.

\section{Características que influyen en la evaluación de la exposición}

De acuerdo con el estudio realizado por el Banco Interamericano de Desarrollo (Cardona, 2005), los indicadores que cumplen mejor la función de medir la exposición y/o susceptibilidad física ante cualquier tipo de desastre son los que reflejan población susceptible, activos, inversiones, producción, medios de sustento, patrimonios esenciales y actividades humanas; también pueden considerarse como indicadores de este tipo los que reflejan tasas de crecimiento y densidad poblacional. Según Füssel (2005), en las evaluaciones de exposición relacionadas con el clima se deben tomar en cuenta las características o factores del sistema expuesto; el tipo y número de factores de estrés y sus causas principales; sus efectos en el sistema, y el horizonte temporal de la evaluación, tal como se indica en la Tabla 2. 
Tecnología y

Ciencias Agua
2022, Instituto Mexicano de Tecnología del Agua Open Access bajo la licencia CC BY-NC-SA 4.0 (https://creativecommons.org/licenses/by-nc$\mathrm{sa} / 4.0 /)$

Tabla 2. Dimensiones fundamentales que describen la situación de la exposición.

\begin{tabular}{|c|c|c|}
\hline $\begin{array}{l}\text { Dimensión o } \\
\text { Característica }\end{array}$ & Pregunta & Opciones posibles \\
\hline Sistema/método & $\begin{array}{l}\text { ¿Quién o } \\
\text { qué está } \\
\text { expuesto? }\end{array}$ & $\begin{array}{l}\text { Una comunidad, una región } \\
\text { geográfica, un sector económico, } \\
\text { un sistema natural }\end{array}$ \\
\hline $\begin{array}{l}\text { Peligro (o amenazas o } \\
\text { factores de estrés) }\end{array}$ & $\begin{array}{l}\text { ¿Expuesto } \\
\text { a qué? }\end{array}$ & $\begin{array}{l}\text { El cambio climático antrópico, } \\
\text { variabilidad natural del clima, la } \\
\text { composición atmosférica, otros } \\
\text { factores no climáticos }\end{array}$ \\
\hline $\begin{array}{l}\text { Las consecuencias (o } \\
\text { efectos o atributos } \\
\text { valorados o variables } \\
\text { de interés) }\end{array}$ & $\begin{array}{l}\text { ¿Qué está } \\
\text { en riesgo? }\end{array}$ & $\begin{array}{l}\text { Viabilidad de los ecosistemas, la } \\
\text { seguridad alimentaria, la salud } \\
\text { humana, los bienes económicos, } \\
\text { otros bienes y servicios valorados }\end{array}$ \\
\hline \multirow{2}{*}{$\begin{array}{l}\text { Escala temporal y } \\
\text { espacial }\end{array}$} & $\begin{array}{c}\text { ¿Qué } \\
\text { horizonte } \\
\text { de tiempo? }\end{array}$ & Meses, años, décadas, siglos \\
\hline & $\begin{array}{l}\text { ¿Qué } \\
\text { región? }\end{array}$ & $\begin{array}{l}\text { Estado, municipio, cuenca, región } \\
\text { hidrológica, país, continente }\end{array}$ \\
\hline
\end{tabular}

Fuente: elaboración propia a partir de Füssel (2005). 
Tecnología y

Ciencias $₫$ Agua
2022, Instituto Mexicano de Tecnología del Agua Open Access bajo la licencia CC BY-NC-SA 4.0 (https://creativecommons.org/licenses/by-nc$\mathrm{sa} / 4.0 /)$

Se ha demostrado que la exposición a la sequía aumenta la pobreza (Carter, Little, Mogues, \& Negatu, 2007; Dercon, 2004). impacto del riesgo de desastre en la pobreza se produce de forma visible (las pérdidas cuando se produce un desastre), así como a través de lo menos obvio: los hogares expuestos al riesgo meteorológico reducen la inversión en activos productivos, y al seleccionar actividades de bajo riesgo y bajo rendimiento (Cole et al., 2013; Elbers, Gunning, \& Kinsey, 2007). Este vínculo de la exposición a la pobreza ante los peligros naturales puede crear un bucle de retroalimentación, en el que los hogares pobres no tienen más remedio que establecerse en zonas de riesgo y, por lo tanto, se enfrentan a mayores desafíos para escapar de la pobreza (Winsemius et al., 2018).

\section{Métodos para calcular la exposición}

Para evaluar la exposición a la sequía, los métodos basados en indicadores socioeconómicos y ambientales son los más ampliamente utilizados; tales indicadores por lo general se combinan entre sí para generar índices compuestos que son representativos de los diferentes grados de exposición (Hagenlocher et al., 2019). Dicho enfoque metodológico contribuye a una mejor comprensión de la multidimensionalidad de esta 
Tecnología y

Ciencias $\stackrel{\mho}{\varpi}$ Agua
2022, Instituto Mexicano de Tecnología del Agua

Open Access bajo la licencia CC BY-NC-SA 4.0 (https://creativecommons.org/licenses/by-nc$\mathrm{sa} / 4.0 /)$

variable, lo cual es especialmente útil para los procesos de toma de decisiones encaminadas a la gestión del riesgo.

\section{Modelos matemáticos}

Algunos trabajos consideran la exposición como una componente de la vulnerabilidad (Burg, 2008; Ortega-Gaucin et al., 2018a; Ortega-Gaucin, De-la-Cruz-Bartolón, \& Castellano-Bahena, 2018b; Fontaine \& Steinemann, 2009) y se basan en la definición de vulnerabilidad del IPCC (2001). Sin embargo, en otras investigaciones se contempla la exposición a la sequía de manera independiente a la vulnerabilidad como una componente del riesgo (Carrao, Naumann, \& Barbosa, 2016; Frischen, Meza, Rupp, Wietler, \& Hagenlocher, 2020; Ortega-Gaucin, CeballosTavares, Ordoñez, \& Castellano-Bahena, 2021) con base en el concepto de riesgo del IPCC (2014). Pero independientemente del marco conceptual adoptado, se han propuesto diversos modelos matemáticos para calcular la exposición. Peduzzi, Dao, Herold y Mouton (2009) presentan un modelo de factores que influyen en los niveles de pérdidas humanas por peligros naturales a escala mundial para el periodo 19802000, cuyo objetivo es monitorear la evolución del riesgo; la combinación de la frecuencia promedio anual de peligros y las poblaciones expuestas proporciona la exposición física. Welle y Birkmann (2015) proporcionan 
Tecnología y

Ciencias Agua
2022, Instituto Mexicano de Tecnología del Agua Open Access bajo la licencia CC BY-NC-SA 4.0 (https://creativecommons.org/licenses/by-nc$\mathrm{sa} / 4.0 /)$

un nuevo enfoque para evaluar el riesgo frente a los peligros naturales a escala de país. Carrao et al. (2016) proponen un modelo no compensatorio de la exposición a la sequía para estimar las pérdidas potenciales de diferentes tipos de desastres por sequía. Winsemius et al. (2018) investigan la exposición global de las personas pobres frente a las inundaciones y sequías en 52 países. Ahmadalipour, Moradkhani, Castelletti y Magliocca (2019) evalúan el riesgo de sequía a nivel nacional en África. Ortega-Gaucin et al. (2021) determinan el riesgo de sequía agrícola en Zacatecas, México. En la Tabla 3 se presentan los modelos matemáticos que utilizan los autores mencionados para calcular la exposición.

Tabla 3. Modelos matemáticos más usuales para calcular la exposición.

\begin{tabular}{|c|c|c|}
\hline Autor & Fórmula & Descripción \\
\hline \multirow[t]{2}{*}{$\begin{array}{l}\text { Peduzzi et al. } \\
\text { (2009) }\end{array}$} & PhExp $=\sum_{i}^{n} F$ Pop $_{i}$ & $\begin{array}{l}\text { Donde PhExp es la exposición física promedio anual para la } \\
\text { unidad espacial (población expuesta/año); } F \text {, la frecuencia } \\
\text { anual de un evento de magnitud dada (evento/año); Popi, la } \\
\text { población total que vive en la unidad espacial para cada } \\
\text { evento "i" (población expuesta/evento); } n \text {, el número de } \\
\text { eventos considerados }\end{array}$ \\
\hline & PhExp $=\sum \frac{P_{o p}}{Y_{n}}$ & $\begin{array}{l}\text { Donde PhExp es la exposición física media anual para la } \\
\text { unidad espacial (población expuesta/año); Popi, la población } \\
\text { que vive en el área afectada para cada evento "i" (población } \\
\text { expuesta/evento); } Y_{n} \text {, el periodo de tiempo (año) }\end{array}$ \\
\hline $\begin{array}{l}\text { Welle y } \\
\text { Birkmann } \\
\text { (2015) }\end{array}$ & $\begin{array}{l}\operatorname{Exp} \\
=\frac{A+B+C+(0.5 * D+E)}{N}\end{array}$ & $\begin{array}{l}\text { Donde } \operatorname{Exp} \text { es la exposición; } A \text {, las personas expuestas a } \\
\text { terremotos; } B \text {, las personas expuestas a tormentas; } C \text {, las } \\
\text { personas expuestas a inundaciones; } D \text {, las personas }\end{array}$ \\
\hline
\end{tabular}


Tecnología y

Ciencias $\approx$ Agua
2022, Instituto Mexicano de Tecnología del Agua

Open Access bajo la licencia CC BY-NC-SA 4.0 (https://creativecommons.org/licenses/by-nc$\mathrm{sa} / 4.0 /)$

\begin{tabular}{|c|c|c|}
\hline & & $\begin{array}{l}\text { expuestas a sequías; } E \text {, las personas expuestas al aumento } \\
\text { del nivel del mar; } N \text {, el número de población }\end{array}$ \\
\hline $\begin{array}{l}\text { Carrao et al. } \\
(2016)\end{array}$ & $d e_{i}=\overline{O R_{i}} / \overline{O R^{\prime}}{ }_{i}^{\prime}$ & $\begin{array}{l}\text { Donde } d e_{i} \text { es la exposición a la sequía; } \overline{O R_{i}} \text {, la distancia } \\
\text { multivariante entre el origen y los valores reales de los } \\
\text { indicadores observados para la región } i ; \overline{O R^{\prime}}{ }^{\prime} \text {, la distancia } \\
\text { entre el origen y los valores regionales proyectados en la } \\
\text { frontera de máxima exposición }\end{array}$ \\
\hline $\begin{array}{l}\text { Winsemius et } \\
\text { al. (2018) }\end{array}$ & $I_{p}=\frac{f_{p}}{f}-1$ & $\begin{array}{l}\text { Donde } I_{P} \text { es el sesgo de exposición a la pobreza (PEB); fp y } \\
f \text {, la fracción de personas expuestas a inundaciones/sequías } \\
\text { en el país, respectivamente }\end{array}$ \\
\hline $\begin{array}{l}\text { Ahmadalipour } \\
\text { et al. (2019) }\end{array}$ & Exp $=\frac{\text { Esposición }_{\text {fut } ; p}}{{\text { Exposición } n_{\text {hist }}}}$ & $\begin{array}{l}\text { Donde Exp es la exposición; hist y fut indican periodos } \\
\text { históricos y futuros; y } p \text {, escenarios de población (baja, } \\
\text { media y alta) }\end{array}$ \\
\hline $\begin{array}{l}\text { Ortega- } \\
\text { Gaucin et al. } \\
\text { (2021) }\end{array}$ & $D E I=\sum_{i=1}^{n} X_{i} W_{i}$ & $\begin{array}{l}\text { Donde } D E I \text { es el índice de exposición a la sequía; } X_{i} \text {, el valor } \\
\text { normalizado del indicador } i ; W_{i} \text {, el peso del indicador } \\
\text { normalizado } i ; n \text {, el número de indicadores de exposición a } \\
\text { la sequía }\end{array}$ \\
\hline
\end{tabular}

Fuente: elaboración propia.

Para que un índice de exposición a la sequía sea de fácil uso y procesamiento, su formulación se debe basar en un número menor de indicadores que reflejen aspectos relevantes $y$ orientadores del tipo de acción que se requiere llevar a cabo por los tomadores de decisiones. Este conjunto de indicadores por sí solos y, sobre todo, desagregados en lo local podrían facilitar la identificación y orientación de las acciones que se deben promover, fortalecer o priorizar para lograr un mayor nivel de seguridad frente 


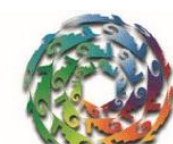

Ciencias $\stackrel{\unlhd}{\unlhd}$ gua
2022, Instituto Mexicano de Tecnología del Agua

Open Access bajo la licencia CC BY-NC-SA 4.0 (https://creativecommons.org/licenses/by-nc$\mathrm{sa} / 4.0 /)$

al peligro. Así, de todos los indicadores posibles, hay que seleccionar un número reducido de ellos con base en la disponibilidad de datos a juicio personal o por investigación previa (Ortega-Gaucin et al., 2018b; Ortega-Gaucin et al., 2021).

\section{Vulnerabilidad ante la sequía}

Las evaluaciones de vulnerabilidad ante la sequía son el primer paso en la identificación de las causas subyacentes que generan los impactos de las mismas (González, Urquijo, Blauhut, Villarroya, \& De-Stefano, 2016). La vulnerabilidad ante una sequía es compleja, por lo que es necesario comprenderla para así poder diseñar estrategias de preparación y mitigación, al igual que políticas y programas de ayuda (Patrick, 2003). A continuación se describen los conceptos y los as pectos metodológicos más utilizados para hacer una evaluación de vulnerabilidad ante la sequía (Figura 4). 
Tecnología y

Ciencias $\stackrel{\unlhd}{\unlhd}$ gua
2022, Instituto Mexicano de Tecnología del Agua

Open Access bajo la licencia CC BY-NC-SA 4.0 (https://creativecommons.org/licenses/by-nc$\mathrm{sa} / 4.0 /$ )

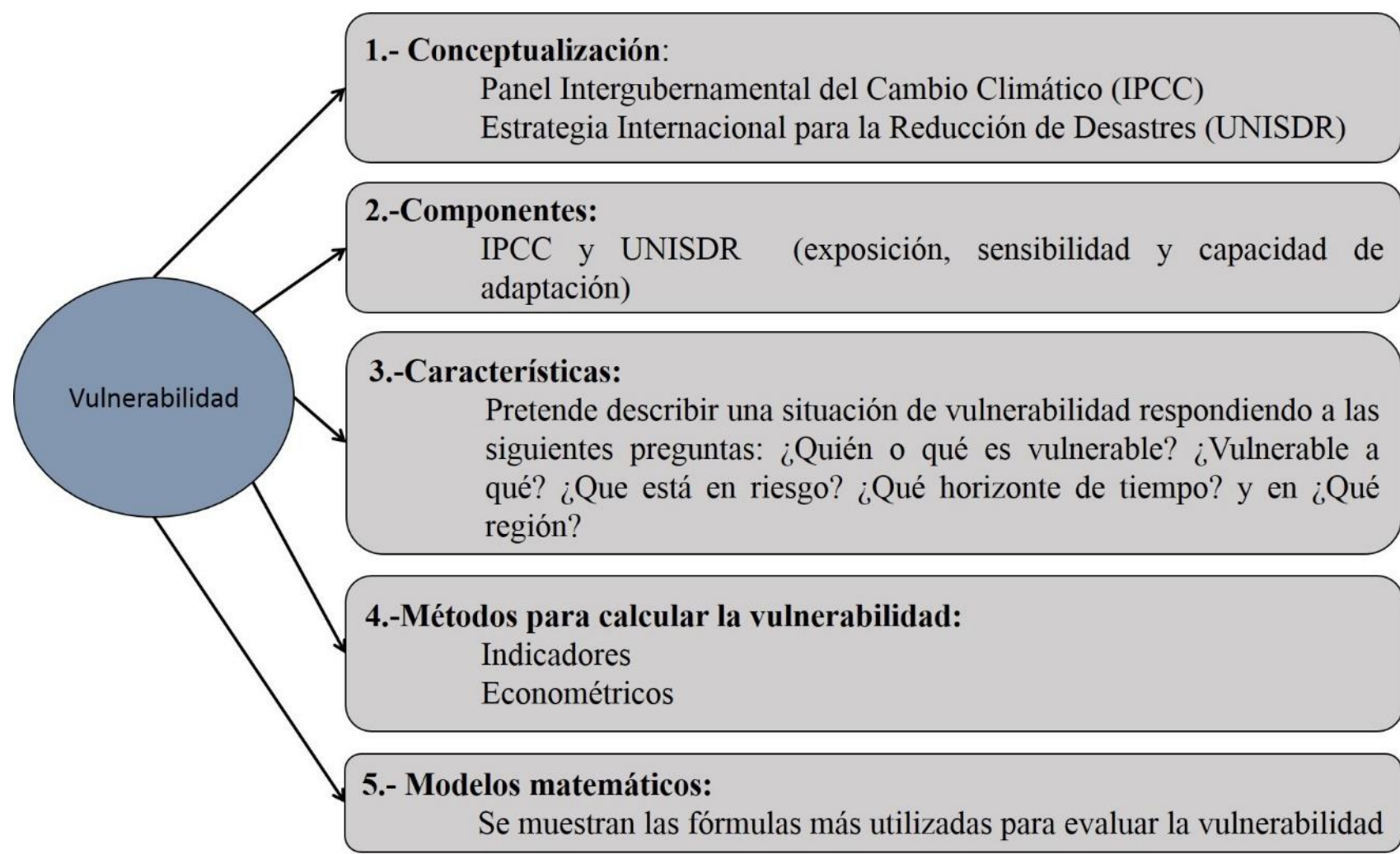

Figura 4. Diagrama metodológico para evaluar la vulnerabilidad ante la sequía. Fuente: elaboración propia.

\section{Conceptualización de vulnerabilidad}

Los conceptos y definiciones de vulnerabilidad han sido analizados por autores como Timmerman (1981); Kates (1985); Chambers (1989); 
Tecnología y

Ciencias $\stackrel{\Xi}{\unlhd}$ gua
2022, Instituto Mexicano de Tecnología del Agua Open Access bajo la licencia CC BY-NC-SA 4.0 (https://creativecommons.org/licenses/by-nc$\mathrm{sa} / 4.0 /)$

Downing (1991); Anderson (1994); Blaikie et al. (1994); Bohle, Downing y Watts (1994); Downing y Bakker (2000), y Birkmann (2007), entre otros. Con base en los conceptos esgrimidos por estos autores se puede afirmar que, de manera general, la vulnerabilidad es una condición de fragilidad o debilidad de un individuo o sistema ante algún tipo de amenaza (sea ésta de origen físico, como las sequías, terremotos, inundaciones; o de tipo antrópico, como los accidentes, devaluaciones, crisis económicas, etc.); tiene un carácter multifacético y multidimensional; es dinámica tanto espacial como temporalmente, y siempre está vinculada con un peligro específico. En este caso, el peligro que nos interesa es el fenómeno de la sequía. Con respecto a ello, González et al. (2016) comentan que la mayoría de las definiciones de vulnerabilidad aplicadas a la sequía y a otros fenómenos climáticos se originan a partir de las definiciones del IPCC (IPCC, 2001; IPCC, 2014) y de la Oficina de las Naciones Unidas para la Reducción del Riesgo de Desastres (UNISDR, 2009), las cuales se muestran en la Tabla 4.

Tabla 4. Definiciones de vulnerabilidad según los enfoques del IPCC y UNISDR.

\begin{tabular}{|l|l|l|l|}
\hline \multirow{2}{*}{ Concepto } & \multicolumn{3}{|c|}{ Origen del concepto } \\
\cline { 2 - 4 } & \multicolumn{2}{|c|}{ IPCC } & \multirow{2}{*}{ UNISDR (2009) } \\
\cline { 2 - 4 } & IPCC (2001) & IPCC (2014) & \\
\hline $\begin{array}{l}\text { Definición de } \\
\text { vulnerabilidad }\end{array}$ & $\begin{array}{l}\text { Nivel al que un } \\
\text { sistema }\end{array}$ & $\begin{array}{l}\text { Propensión o } \\
\text { predisposición }\end{array}$ & $\begin{array}{l}\text { Las características y } \\
\text { circunstancias de una }\end{array}$ \\
\hline
\end{tabular}


Tecnología y

Ciencias $₫$ Agua
2022, Instituto Mexicano de Tecnología del Agua Open Access bajo la licencia CC BY-NC-SA 4.0 (https://creativecommons.org/licenses/by-nc$\mathrm{sa} / 4.0 /)$

\begin{tabular}{|c|c|c|c|}
\hline \multirow{4}{*}{ Concepto } & \multicolumn{3}{|c|}{ Origen del concepto } \\
\hline & \multicolumn{2}{|c|}{ IPCC } & \multirow{3}{*}{$\begin{array}{l}\text { UNISDR (2009) } \\
\text { comunidad, sistema o } \\
\text { bien que los hacen } \\
\text { susceptibles a los } \\
\text { efectos dañinos de } \\
\text { una amenaza }\end{array}$} \\
\hline & IPCC (2001) & IPCC (2014) & \\
\hline & $\begin{array}{lrr}\text { susceptible } & \text { o } & \text { no } \\
\text { es capaz } & \text { de } \\
\text { soportar } & \text { los } \\
\text { efectos } & \text { adversos } \\
\text { del } & \text { cambio } \\
\text { climático, } & \\
\text { incluidos } & \text { la } \\
\text { variabilidad } & \\
\text { climática y } & \text { los } \\
\text { fenómenos } & \\
\text { extremos } & \end{array}$ & $\begin{array}{l}\text { a ser } \\
\text { afectado de } \\
\text { manera } \\
\text { negativa }\end{array}$ & \\
\hline Objetivo & $\begin{array}{ll}\text { Considera } & \text { la } \\
\text { evaluación de } & \text { la } \\
\text { vulnerabilidad } & \\
\text { como el resultado } \\
\text { esperado r del } \\
\text { análisis }\end{array}$ & $\begin{array}{lr}\text { Pone énfasis } \\
\text { en } & \text { cómo } \\
\text { reducir r y } \\
\text { gestionar } & \text { los } \\
\text { riesgos } & \text { del } \\
\text { cambio } & \\
\text { climático } & \end{array}$ & $\begin{array}{llr}\text { Tiene por objeto } \\
\text { poner de relieve los } \\
\text { medios para la } \\
\text { reducción del riesgo } \\
\text { de desastres } \\
\text { Considera a la } \\
\text { vulnerabilidad como } \\
\text { un paso dentro de } \\
\text { proceso }\end{array}$ \\
\hline
\end{tabular}


Tecnología y

Ciencias $₫$ Agua
2022, Instituto Mexicano de Tecnología del Agua

Open Access bajo la licencia CC BY-NC-SA 4.0 (https://creativecommons.org/licenses/by-nc$\mathrm{sa} / 4.0 /)$

Fuente: elaboración propia a partir de IPCC (IPCC, 2001; IPCC, 2014), González et al. (2016) y Brooks (2003).

Con base en los conceptos anteriores, la vulnerabilidad ante la sequía se puede entender como el grado en que un sistema es susceptible e incapaz de hacer frente a los efectos adversos, daños o perjuicios causados por este fenómeno natural. De esta manera, la vulnerabilidad se vincula con los impactos potenciales ocasionados por los episodios de sequía, y ha sido utilizada para evaluar la susceptibilidad de los sistemas socioeconómicos y ambientales ante esta amenaza. Algunos ejemplos donde se aplica la definición del IPCC (2001) son los trabajos elaborados por Chandrasekar et al. (2009); Deems (2010); Flörke, Wimmer y Laaser (2011); Antwi-Agyei, Fraser, Dougill, Stringer y Simelton, (2012), y De-Stefano, González, Ballesteros, Urquijo y Blauhut (2015). Asimismo, la definición del IPCC (2014) es empleada por Bouroncle et al. (2016), Guo et al. (2019), Meza et al. (2020), y Frischen et al. (2020). Finalmente, con respecto a la definición de la UNISDR (2009), algunos ejemplos de su uso se encuentran en los trabajos elaborados por Iglesias, Moneo y Quiroga, (2007); Adepetu y Berthe (2007); Cheng y Tao (2010); Zarafshani et al. (2012); Naumann, Barbosa, Garrote, Iglesias y Vogt (2013), y Safavi, Esfahani y Zamani (2014). 
Tecnología y

Ciencias $₫$ Agua
2022, Instituto Mexicano de Tecnología del Agua

Open Access bajo la licencia CC BY-NC-SA 4.0 (https://creativecommons.org/licenses/by-nc$\mathrm{sa} / 4.0 /)$

\section{Componentes de la vulnerabilidad}

Originalmente, el IPCC (2001) propuso el concepto de vulnerabilidad como una función de la exposición de un sistema a la variación climática, de su sensibilidad y de su capacidad de adaptación. Sin embargo, en su quinto informe de evaluación, el IPCC (2014) modificó la concepción de estos términos, dejando a la vulnerabilidad solamente en función de la sensibilidad y capacidad de adaptación de un sistema (Figura 5a). El componente de exposición pasó a formar parte del concepto de riesgo, tal como se describirá más adelante. Por su parte, la UNISDR (2009) afirma que las componentes de la vulnerabilidad son la exposición y capacidad de adaptación (Figura 5b). En la Tabla 5 se describen cada uno de los componentes mencionados en función del origen del concepto.

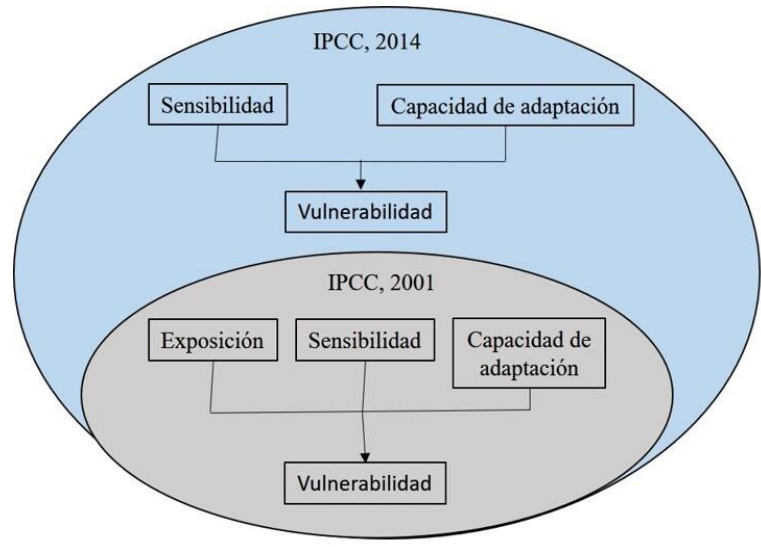

(a)

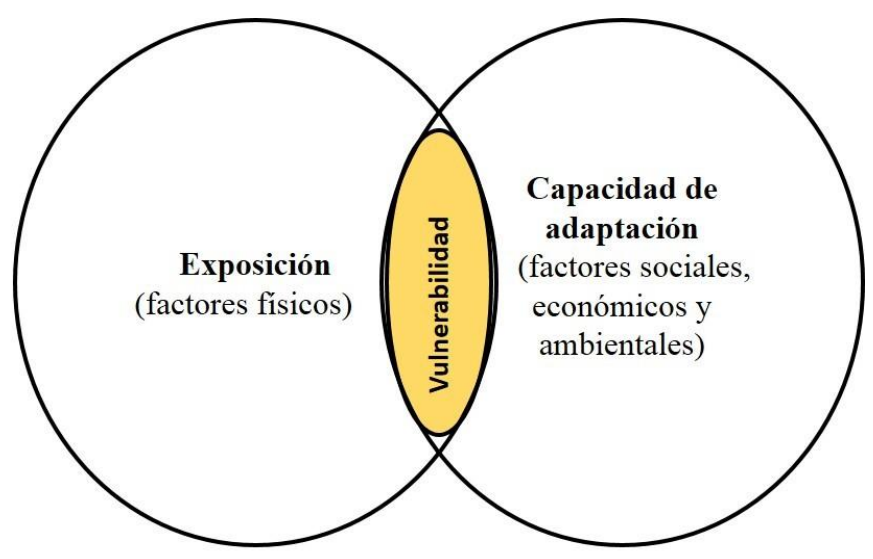

(b) 
Teçnología y

Ciencias $\stackrel{\mho}{\mho}$ Agua
2022, Instituto Mexicano de Tecnología del Agua Open Access bajo la licencia CC BY-NC-SA 4.0 (https://creativecommons.org/licenses/by-nc$\mathrm{sa} / 4.0 /)$

Figura 5. Componentes de la vulnerabilidad según los enfoques del IPCC (a) y la UNISDR (b). Fuente: elaboración propia a partir de IPCC (IPCC, 2001; IPCC, 2014) y UNISDR (2009).

Tabla 5. Componentes de la vulnerabilidad según los enfoques del IPCC y la UNISDR.

\begin{tabular}{|c|c|c|c|}
\hline \multirow{2}{*}{$\begin{array}{c}\text { Origen } \\
\text { del } \\
\text { concepto }\end{array}$} & \multicolumn{3}{|c|}{ Componentes } \\
\hline & Exposición & Sensibilidad & $\begin{array}{c}\text { Capacidad de } \\
\text { adaptación }\end{array}$ \\
\hline $\begin{array}{l}\text { IPCC } \\
(2001)\end{array}$ & $\begin{array}{l}\text { Grado en que un } \\
\text { sistema está } \\
\text { expuesto a } \\
\text { variaciones } \\
\text { climáticas } \\
\text { importantes }\end{array}$ & $\begin{array}{l}\text { Es el grado por el } \\
\text { que está } \\
\text { afectado un } \\
\text { sistema, en } \\
\text { sentido } \\
\text { perjudicial o en } \\
\text { sentido } \\
\text { beneficioso, por } \\
\text { razón de } \\
\text { estímulos } \\
\text { relacionados con } \\
\text { el clima }\end{array}$ & $\begin{array}{l}\text { Es la habilidad de un } \\
\text { sistema de ajustarse } \\
\text { al cambio climático } \\
\text { (incluida la } \\
\text { variabilidad del clima y } \\
\text { sus extremos) para } \\
\text { moderar daños } \\
\text { posibles, aprovecharse } \\
\text { de oportunidades o } \\
\text { enfrentarse a las } \\
\text { consecuencias }\end{array}$ \\
\hline $\begin{array}{l}\text { IPCC } \\
(2014)\end{array}$ & $\begin{array}{l}\text { La presencia de } \\
\text { personas; } \\
\text { medios de }\end{array}$ & $\begin{array}{l}\text { Es el grado en } \\
\text { que un sistema } \\
\text { se ve afectado, }\end{array}$ & $\begin{array}{l}\text { Es el proceso de } \\
\text { ajuste al clima real o } \\
\text { proyectado, y sus }\end{array}$ \\
\hline
\end{tabular}


Tecnología y

Ciencias Agua
2022, Instituto Mexicano de Tecnología del Agua Open Access bajo la licencia CC BY-NC-SA 4.0 (https://creativecommons.org/licenses/by-nc$\mathrm{sa} / 4.0 /)$

\begin{tabular}{|c|c|c|c|}
\hline \multirow{2}{*}{$\begin{array}{c}\text { Origen } \\
\text { del } \\
\text { concepto }\end{array}$} & \multicolumn{3}{|c|}{ Componentes } \\
\hline & Exposición & Sensibilidad & $\begin{array}{c}\text { Capacidad de } \\
\text { adaptación }\end{array}$ \\
\hline & $\begin{array}{l}\text { subsistencia; } \\
\text { especies o } \\
\text { ecosistemas; } \\
\text { funciones, } \\
\text { servicios y } \\
\text { recursos } \\
\text { ambientales; } \\
\text { infraestructura; } \\
\text { o activos } \\
\text { económicos, } \\
\text { sociales o } \\
\text { culturales en } \\
\text { lugares y } \\
\text { entornos que } \\
\text { podrían verse } \\
\text { afectados de } \\
\text { forma negativa }\end{array}$ & $\begin{array}{l}\text { ya sea de modo } \\
\text { adverso o } \\
\text { beneficioso, por } \\
\text { estímulos de } \\
\text { cambio climático }\end{array}$ & $\begin{array}{l}\text { efectos. En los } \\
\text { sistemas humanos, la } \\
\text { adaptación trata de } \\
\text { moderar o evitar los } \\
\text { daños, o aprovechar } \\
\text { las oportunidades } \\
\text { beneficiosas. En } \\
\text { algunos sistemas } \\
\text { naturales, la } \\
\text { intervención humana } \\
\text { puede facilitar el } \\
\text { ajuste al clima } \\
\text { proyectado y sus } \\
\text { efectos }\end{array}$ \\
\hline $\begin{array}{l}\text { UNISDR } \\
(2009)\end{array}$ & $\begin{array}{l}\text { Se refiere a la } \\
\text { población, } \\
\text { propiedades, } \\
\text { sistemas u otros } \\
\text { elementos }\end{array}$ & & $\begin{array}{l}\text { Habilidad de la } \\
\text { población, } \\
\text { organizaciones y } \\
\text { sistemas mediante el } \\
\text { uso de recursos y }\end{array}$ \\
\hline
\end{tabular}


Tecnología y

Ciencias Agua
2022, Instituto Mexicano de Tecnología del Agua Open Access bajo la licencia CC BY-NC-SA 4.0 (https://creativecommons.org/licenses/by-nc$\mathrm{sa} / 4.0 /)$

\begin{tabular}{|c|c|c|c|}
\hline \multirow{2}{*}{$\begin{array}{c}\text { Origen } \\
\text { del } \\
\text { concepto }\end{array}$} & \multicolumn{3}{|c|}{ Componentes } \\
\hline & Exposición & Sensibilidad & $\begin{array}{c}\text { Capacidad de } \\
\text { adaptación }\end{array}$ \\
\hline & $\begin{array}{l}\text { presentes en las } \\
\text { zonas donde } \\
\text { existen } \\
\text { amenazas y, por } \\
\text { consiguiente, } \\
\text { están expuestos } \\
\text { a experimentar } \\
\text { pérdidas } \\
\text { potenciales. Las } \\
\text { medidas del } \\
\text { grado de } \\
\text { exposición } \\
\text { pueden incluir la } \\
\text { cantidad de } \\
\text { personas o los } \\
\text { tipos de bienes } \\
\text { en una zona }\end{array}$ & & $\begin{array}{l}\text { destrezas disponibles } \\
\text { de enfrentary } \\
\text { gestionar condiciones } \\
\text { adversas, situaciones } \\
\text { de emergencia o } \\
\text { desastres }\end{array}$ \\
\hline
\end{tabular}

Fuente: elaboración propia a partir de IPCC (IPCC, 2001; IPCC, 2014) y UNISDR (2009).

De los enfoques conceptuales anteriores, el más aceptado y utilizado por la comunidad científica en los últimos años es el 
Tecnología y

Ciencias $\stackrel{\Xi}{\Im}$ Aua
2022, Instituto Mexicano de Tecnología del Agua Open Access bajo la licencia CC BY-NC-SA 4.0 (https://creativecommons.org/licenses/by-nc$\mathrm{sa} / 4.0 /)$

propuesto por el IPCC (2014), el cual define la vulnerabilidad en función de la sensibilidad y capacidad de adaptación de los sistemas analizados, tal como se puede observar en la creciente cantidad de investigaciones que lo utilizan (Bouroncle et al., 2016; Guo et al., 2019; Frischen et al., 2020; Meza et al., 2020, entre otros).

\section{Características que influyen en la evaluación de la vulnerabilidad}

De acuerdo con Füssel (2005), en las evaluaciones de vulnerabilidad relacionadas con el clima se deben tomar en cuenta las características o factores del sistema vulnerable, tipo y número de factores de estrés y sus causas principales, efectos en el sistema y el horizonte temporal de la evaluación, tal como se indica en la Tabla 6.

Tabla 6. Características fundamentales que describen una situación de vulnerabilidad.

\begin{tabular}{|c|c|l|}
\hline Característica & Pregunta & \multicolumn{1}{|c|}{ Opciones posibles } \\
\hline Sistema/método & $\begin{array}{c}\text { ¿Quién o qué } \\
\text { es } \\
\text { vulnerable? }\end{array}$ & $\begin{array}{l}\text { Una comunidad, una región } \\
\text { geográfica, un sector económico, un } \\
\text { sistema natural }\end{array}$ \\
\hline
\end{tabular}


Tecnología y

Ciencias $\stackrel{\Xi}{\triangleleft}$ gua
2022, Instituto Mexicano de Tecnología del Agua Open Access bajo la licencia CC BY-NC-SA 4.0 (https://creativecommons.org/licenses/by-nc$\mathrm{sa} / 4.0 /)$

\begin{tabular}{|c|c|c|}
\hline Característica & Pregunta & Opciones posibles \\
\hline $\begin{array}{l}\text { Peligro (o amenazas o } \\
\text { factores de estrés) }\end{array}$ & $\begin{array}{c}\text { ¿Vulnerable a } \\
\text { qué? }\end{array}$ & $\begin{array}{l}\text { Cambio climático antrópico, } \\
\text { variabilidad natural del clima, } \\
\text { composición atmosférica, otros } \\
\text { factores no climáticos }\end{array}$ \\
\hline $\begin{array}{l}\text { Las consecuencias (o } \\
\text { efectos o atributos } \\
\text { valorados o variables de } \\
\text { interés) }\end{array}$ & $\begin{array}{l}\text { ¿Qué está en } \\
\text { riesgo? }\end{array}$ & $\begin{array}{l}\text { Viabilidad de los ecosistemas, } \\
\text { seguridad alimentaria, salud } \\
\text { humana, bienes económicos, otros } \\
\text { bienes y servicios valorados }\end{array}$ \\
\hline \multirow[t]{2}{*}{ Escala } & $\begin{array}{l}\text { Tiempo: ¿Qué } \\
\text { horizonte de } \\
\text { tiempo? }\end{array}$ & Años, décadas, siglos \\
\hline & $\begin{array}{c}\text { Espacial: } \\
\text { ¿Qué región? }\end{array}$ & $\begin{array}{l}\text { Estado, municipio, cuenca, región } \\
\text { hidrológica, país, continente }\end{array}$ \\
\hline
\end{tabular}

Fuente: adaptada de Füssel (2004).

\section{Métodos para calcular la vulnerabilidad}

Los métodos más utilizados en la literatura relativa al cambio climático son el método econométrico y los métodos basados en indicadores (Tabla 7). El método econométrico tiene sus raíces en la literatura de la pobreza y el desarrollo; hace uso de los datos de encuestas socioeconómicas en 
Tecnología y

Ciencias $\stackrel{\Xi}{\unlhd}$ gua
2022, Instituto Mexicano de Tecnología del Agua Open Access bajo la licencia CC BY-NC-SA 4.0 (https://creativecommons.org/licenses/by-nc$\mathrm{sa} / 4.0 /)$

hogares para analizar el nivel de vulnerabilidad de los diferentes grupos sociales (Hoddinott \& Quisumbing, 2003). Los métodos basados en indicadores se fundamentan en la selección de algunas variables de todo el conjunto de indicadores potenciales para después combinarlas sistemáticamente, a fin de evaluar los niveles de vulnerabilidad (Cutter, Boruff, \& Shirley, 2003; Kaly \& Pratt, 2000).

Tabla 7. Métodos para calcular la vulnerabilidad.

\begin{tabular}{|c|c|c|}
\hline Concepto & Método econométrico & $\begin{array}{c}\text { Métodos basados en } \\
\text { indicadores }\end{array}$ \\
\hline Descripción & $\begin{array}{l}\text { El método se divide en tres } \\
\text { categorías: la vulnerabilidad como } \\
\text { la pobreza esperada (VEP), la } \\
\text { vulnerabilidad de utilidad baja } \\
\text { esperada (VEU), y la } \\
\text { vulnerabilidad como la exposición } \\
\text { al riesgo no asegurado (VER) } \\
\text { (Hoddinott \& Quisumbing, 2003). } \\
\text { Con estas categorías se construye } \\
\text { una medida de la pérdida de } \\
\text { bienestar atribuido a desastres } \\
\text { (Deressa, Hassan, \& Ringler, } \\
\text { 2008) }\end{array}$ & $\begin{array}{l}\text { Se basan en } \\
\text { seleccionar algunos } \\
\text { indicadores de todo el } \\
\text { conjunto de } \\
\text { indicadores potenciales } \\
\text { y luego combinarlos } \\
\text { sistemáticamente para } \\
\text { determinar los niveles } \\
\text { de vulnerabilidad } \\
\text { (Deressa et al., 2008) }\end{array}$ \\
\hline Ventajas & $\begin{array}{l}\text { El método es fácil de estimar. Con } \\
\text { el cálculo de VEP se pueden }\end{array}$ & $\begin{array}{l}\text { Este método es valioso } \\
\text { para monitorear }\end{array}$ \\
\hline
\end{tabular}


Tecnología y

Ciencias $\stackrel{\Xi}{\varpi}$ gua
2022, Instituto Mexicano de Tecnología del Agua Open Access bajo la licencia CC BY-NC-SA 4.0 (https://creativecommons.org/licenses/by-nc$\mathrm{sa} / 4.0 /)$

\begin{tabular}{|c|c|c|}
\hline Concepto & Método econométrico & $\begin{array}{c}\text { Métodos basados en } \\
\text { indicadores }\end{array}$ \\
\hline & $\begin{array}{l}\text { identificar los hogares en riesgo } \\
\text { que no son pobres; el cálculo del } \\
\text { VEU } \quad \text { proporciona }\end{array}$ & $\begin{array}{l}\text { tendencias y explorar } \\
\text { marcos conceptuales } \\
\text { (Deressa et al., 2008). } \\
\text { Integra y resume } \\
\text { diferentes dimensiones } \\
\text { de un tema, son fáciles } \\
\text { de interpretar, y facilita } \\
\text { la evaluación de la } \\
\text { eficacia de las políticas } \\
\text { y la rendición de } \\
\text { cuentas por parte de } \\
\text { los representantes del } \\
\text { gobierno (Schuschny \& } \\
\text { Soto, 2009) }\end{array}$ \\
\hline Desventajas & $\begin{array}{l}\text { Si las estimaciones se realizan } \\
\text { utilizando una única sección } \\
\text { transversal se debe suponer que } \\
\text { la variabilidad transversal captura } \\
\text { la variabilidad remporal } \\
\text { (Hoddinott \& Quisumbing, 2003), } \\
\text { además es difícil explicarel tipo de } \\
\text { riesgo de un individuo, dado que } \\
\text { los individuos están mal }\end{array}$ & $\begin{array}{l}\text { Conducen a una falta } \\
\text { de correspondencia } \\
\text { entre la definición } \\
\text { conceptual de } \\
\text { vulnerabilidad y las } \\
\text { métricas (Deressa et } \\
\text { al.,2008) }\end{array}$ \\
\hline
\end{tabular}


Tecnología y

Ciencias $₫$ Agua
2022, Instituto Mexicano de Tecnología del Agua Open Access bajo la licencia CC BY-NC-SA 4.0 (https://creativecommons.org/licenses/by-nc$\mathrm{sa} / 4.0 /)$

\begin{tabular}{|c|c|c|}
\hline Concepto & Método econométrico & $\begin{array}{c}\text { Métodos basados en } \\
\text { indicadores }\end{array}$ \\
\hline & $\begin{array}{l}\text { informados acerca de ellos } \\
\text { (Kanbur, 1987); a falta de } \\
\text { conjuntos de datos, las } \\
\text { estimaciones de los impactos a } \\
\text { menudo son parciales y, por lo } \\
\text { tanto, no son indicadores } \\
\text { concluyentes (Deressa et al., } \\
2008 \text { ) }\end{array}$ & \\
\hline
\end{tabular}

Fuente: elaboración propia.

De manera similar a la exposición a la sequía, los métodos basados en indicadores socioeconómicos y ambientales son los que más se utilizan para evaluar la vulnerabilidad; estos indicadores se combinan entre sí para generar índices compuestos representativos de los diferentes grados de vulnerabilidad (Hagenlocher et al., 2019). Este enfoque permite comprender mejor las diferentes facetas de esta variable, y orientar las acciones dirigidas a su reducción mediante la implementación de medidas preventivas y de mitigación de la sequía.

\section{Modelos matemáticos}


Teçnología y

Ciencias $\stackrel{\unlhd}{\unlhd}$ gua
2022, Instituto Mexicano de Tecnología del Agua Open Access bajo la licencia CC BY-NC-SA 4.0 (https://creativecommons.org/licenses/by-nc$\mathrm{sa} / 4.0 /)$

Dado que la vulnerabilidad se manifiesta en lugares y momentos específicos (Adger, 2006), existen diversos modelos matemáticos para calcularla. En este caso se observan algunas similitudes que tienen los modelos que se presentan en esta sección, por ejemplo: los modelos de Webb y Harinarayan (1999), y del IPCC (IPCC, 2001; IPCC, 2014) reconocen a la capacidad de adaptación como parte importante en mitigar el impacto de la amenaza; en el caso de Fontaine y Steinemann (2009), modificaron el modelo del IPCC (2001), donde la exposición y sensibilidad se suman y el resultado se divide entre la capacidad de adaptación; Luers, Lobell, Sklar, Addams y Matson (2003) miden la vulnerabilidad en función del estado de las variables de interés en relación con un umbral de daño, la sensibilidad de las variables a los factores estresantes, y la magnitud y frecuencia de los factores estresantes a los que está expuesto el sistema; Me-Bar y Valdez (2005) ven a la vulnerabilidad como el nivel del umbral para un desastre; Burg (2008) concibe a la vulnerabilidad como la probabilidad de una disminución aguda o déficit crónico de acceso a los alimentos o el consumo por debajo de un valor crítico; Ortega-Gaucin et al. (2018a y 2018b) desarrollan un índice de vulnerabilidad global a la sequía que incluye la vulnerabilidad económica, social y ambiental de los sistemas analizados; y Ortega-Gaucin et al. (2021) proponen evaluar la vulnerabilidad de los sistemas agrícolas ante la sequía en función de los índices de sensibilidad y capacidad de adaptación. En la Tabla 8 se 
Tecnología y

Ciencias $\stackrel{\unlhd}{\unlhd}$ gua
2022, Instituto Mexicano de Tecnología del Agua

Open Access bajo la licencia CC BY-NC-SA 4.0 (https://creativecommons.org/licenses/by-nc$\mathrm{sa} / 4.0 /)$

presentan los modelos matemáticos más comunes para calcular la vulnerabilidad.

Tabla 8. Modelos matemáticos más usuales para calcular la vulnerabilidad.

\begin{tabular}{|c|c|c|}
\hline Autor & Descripción & Formula \\
\hline $\begin{array}{l}\text { Webb \& } \\
\text { Harinarayan } \\
\text { (1999) }\end{array}$ & $\begin{array}{l}\text { Utilizaron la fórmula } \\
\text { para estudiar la } \\
\text { relación entre } \\
\text { vulnerabilidad y } \\
\text { desnutrición }\end{array}$ & $\begin{array}{l}\qquad V=H-C A \\
\text { Donde } H \text { es peligro o amenaza, y } C A \\
\text { es la capacidad de adaptación }\end{array}$ \\
\hline $\begin{array}{l}\text { IPCC } \\
(2001)\end{array}$ & $\begin{array}{l}\text { Proporciona una } \\
\text { definición operativa } \\
\text { de la vulnerabilidad }\end{array}$ & \begin{tabular}{l}
\multicolumn{4}{c}{$V=C A-(S+E)$} \\
Donde $C A$ es la capacidad de \\
adaptación; $S$, sensibilidad; $E$, \\
exposición
\end{tabular} \\
\hline $\begin{array}{l}\text { Luers et al. } \\
\text { (2003) }\end{array}$ & $\begin{array}{l}\text { Examina la } \\
\text { vulnerabilidad de los } \\
\text { sistemas } \\
\text { socioecológicos }\end{array}$ & $\begin{array}{l}\qquad V=\frac{S E}{E R A X P O E} \\
\text { Donde } V \text { es vulnerabilidad; } S E \text {, } \\
\text { sensibilidad al estrés; } E R A \text {, estado } \\
\text { relativo al umbral; } P O E, \\
\text { probabilidad de ocurrencia de estrés }\end{array}$ \\
\hline $\begin{array}{l}\text { Me-Bar y } \\
\text { Valdez } \\
(2005)\end{array}$ & $\begin{array}{ll}\text { Proporcionaron } & \text { un } \\
\text { modelo que fue } \\
\text { utilizado } & \text { por }\end{array}$ & $V_{i=\frac{1}{C_{i}}} \sum_{j=1}^{k_{i}}\left(P_{j} * W_{j}\right)$ \\
\hline
\end{tabular}


Tecnología y

Ciencias Agua
2022, Instituto Mexicano de Tecnología del Agua Open Access bajo la licencia CC BY-NC-SA 4.0 (https://creativecommons.org/licenses/by-nc$\mathrm{sa} / 4.0 /)$

\begin{tabular}{|c|c|c|}
\hline Autor & Descripción & Formula \\
\hline & $\begin{array}{l}\text { Zarafshani et al. } \\
\text { (2012) para evaluar } \\
\text { la vulnerabilidad de } \\
\text { los productores de } \\
\text { trigo a la sequía }\end{array}$ & $\begin{array}{l}\text { Donde } P \text { en esta fórmula es un valor } \\
\text { de parámetro; } W \text {, un peso asignado } \\
\text { a cada parámetro; } C \text { se deriva de } C i \\
=1 / 2(W \text { máx } k i) \text { a la suma de todos } \\
\text { los pesos, donde } W \text { máx es el valor } \\
\text { máximo de la escala de peso }\end{array}$ \\
\hline $\begin{array}{l}\text { Burg } \\
(2008)\end{array}$ & $\begin{array}{l}\text { Propone el índice de } \\
\text { vulnerabilidad } \\
\text { crónica (CVI) para } \\
\text { medir los niveles de } \\
\text { vulnerabilidad a la } \\
\text { inseguridad } \\
\text { alimentaria }\end{array}$ & $\begin{array}{l}\qquad V=E+I \\
\text { Donde } E \text { es la exposición al riesgo e } \\
I \text { es la incapacidad para hacer frente }\end{array}$ \\
\hline $\begin{array}{l}\text { Fontaine y } \\
\text { Steinemann } \\
(2009)\end{array}$ & 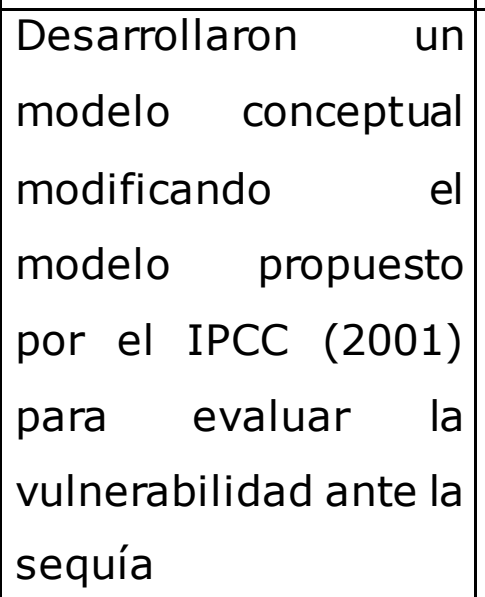 & $\begin{array}{l}\qquad V=\frac{E+S}{C A} \\
\text { Donde } E \text { es la exposición; } S \text {, } \\
\text { sensibilidad; } C A \text {, la capacidad de } \\
\text { adaptación }\end{array}$ \\
\hline $\begin{array}{l}\text { IPCC } \\
(2014)\end{array}$ & $\begin{array}{l}\text { Modifica la definición } \\
\text { operativa de la }\end{array}$ & $V=S-C A$ \\
\hline
\end{tabular}


Tecnología y

Ciencias $₫$ Agua
2022, Instituto Mexicano de Tecnología del Agua Open Access bajo la licencia CC BY-NC-SA 4.0 (https://creativecommons.org/licenses/by-nc$\mathrm{sa} / 4.0 /)$

\begin{tabular}{|c|c|c|}
\hline Autor & Descripción & Formula \\
\hline & $\begin{array}{l}\text { vulnerabilidad que se } \\
\text { realizó en } 2001\end{array}$ & $\begin{array}{l}\text { Donde } S \text { es sensibilidad; } C A \text {, } \\
\text { capacidad de adaptación }\end{array}$ \\
\hline $\begin{array}{l}\text { Ortega- } \\
\text { Gaucin et } \\
\text { al. (2018a y } \\
2018 b)\end{array}$ & $\begin{array}{l}\text { Proponen un índice } \\
\text { de vulnerabilidad } \\
\text { global ante la sequía } \\
\text { que incluye la } \\
\text { vulnerabilidad } \\
\text { económica, social y } \\
\text { ambiental }\end{array}$ & $\begin{array}{l}\qquad I V G=\frac{I V E}{3}+\frac{I V S}{3}+\frac{I V A}{3} \\
\text { Donde IVG es el índice de } \\
\text { vulnerabilidad global antela sequía; } \\
I V E, \text { el índice de vulnerabilidad } \\
\text { económica; IVS, el índice de } \\
\text { vulnerabilidad social; e IVA es el } \\
\text { índice de vulnerabilidad ambiental. } \\
\text { El IVG se calcula asumiendo un peso } \\
P_{i} \text { de } 1 / 3 \text { para cada una de sus } \\
\text { componentes }\end{array}$ \\
\hline $\begin{array}{l}\text { Ortega- } \\
\text { Gaucin et } \\
\text { al. (2021) }\end{array}$ & $\begin{array}{l}\text { Desarrollan un índice } \\
\text { de vulnerabilidad } \\
\text { ante la sequía } \\
\text { agrícola evaluado en } \\
\text { función de los índices } \\
\text { de sensibilidad y } \\
\text { capacidad } \\
\text { adaptación }\end{array}$ & $\begin{array}{l}\qquad D V I=\frac{S I+(1-A C I)}{2} \\
\text { Donde DVI es el índice de } \\
\text { vulnerabilidad a la sequía agrícola; } \\
S I \text {, índice de sensibilidad; y } A C I \text { es } \\
\text { el índice de capacidad de adaptación }\end{array}$ \\
\hline
\end{tabular}

Fuente: elaboración propia. 
Tecnología y

Ciencias $\stackrel{\unlhd}{\unlhd}$ gua
2022, Instituto Mexicano de Tecnología del Agua Open Access bajo la licencia CC BY-NC-SA 4.0 (https://creativecommons.org/licenses/by-nc$\mathrm{sa} / 4.0 /)$

De los modelos matemáticos anteriores, el que ha sido más aceptado y usado por la comunidad académica internacional es el propuesto por el IPCC (2014), el cual modifica la definición operativa de la vulnerabilidad que realizó este mismo organismo en 2001, expresándola en función de la sensibilidad y capacidad de adaptación (dejando fuera la componente de exposición, que pasó a formar parte del concepto de riesgo).

Así, a partir de la combinación de los análisis de exposición, vulnerabilidad y amenaza de un sistema específico, es posible determinar el nivel de riesgo de ese sistema ante la sequía, con base en los conceptos de riesgo que se describen a continuación.

\section{Riesgo}

El concepto de riesgo, asociado con la idea de porvenir sin certeza, ha estado presente desde siempre en las sociedades humanas (Cardona, 2001). En este apartado se describen las diferentes definiciones de riesgo y los modelos matemáticos para calcularlo. 
Tecnología y

Ciencias $\approx$ Agua
2022, Instituto Mexicano de Tecnología del Agua Open Access bajo la licencia CC BY-NC-SA 4.0 (https://creativecommons.org/licenses/by-nc$\mathrm{sa} / 4.0 /)$

\section{Definiciones de riesgo}

La extinta Organización de las Naciones Unidas para el Socorro en Desastres (UNDRO, 1979) contempla dos definiciones de riesgo que se consideran la base de los conceptos actuales; la primera es el riesgo específico y la segunda es el riesgo total: a) riesgo específico (specific risk-Rs): grado de pérdidas esperadas debido a la ocurrencia de un evento particular, y como una función de la amenaza y la vulnerabilidad; b) riesgo total (total risk-Rt): número de pérdidas humanas, heridos, daños a las propiedades y efectos sobre la actividad económica debido a la ocurrencia de un evento desastroso, es decir, el producto del riesgo específico $(R s)$ y los elementos bajo riesgo $(E)$. Por su parte, la UNISDR (2009) define el riesgo como las posibles pérdidas que ocasionaría un desastre en términos de vidas, condiciones de salud, medios de sustento, bienes y servicios, y que podrían ocurrir en una comunidad o sociedad particular en un periodo específico de tiempo en el futuro. Por último, el IPCC (2014) define el riesgo como potencial de consecuencias en que algo de valor está en peligro con un desenlace incierto, reconociendo la diversidad de valores. A menudo el riesgo se representa como la probabilidad de acaecimiento de sucesos o tendencias peligrosos multiplicada por los impactos en caso de que ocurran tales sucesos o tendencias. Los riesgos resultan de la interacción de vulnerabilidad, exposición y peligro. El término riesgo se utiliza principalmente en referencia a los riesgos de impactos del cambio climático. 
Tecnología y

Ciencias $₫$ Agua
2022, Instituto Mexicano de Tecnología del Agua

Open Access bajo la licencia CC BY-NC-SA 4.0 (https://creativecommons.org/licenses/by-nc$\mathrm{sa} / 4.0 /)$

\section{Modelos matemáticos para calcular el riesgo}

Existen diferentes marcos y ecuaciones para evaluar el riesgo. En este apartado se explican algunos modelos, por ejemplo, Yen (1971) calcula el riesgo como la probabilidad de un evento adverso; la UNDRO (1979) determina el riesgo en función de la exposición, amenaza y vulnerabilidad; Cardona (1985), y Schneiderbauer y Ehrlich (2004) tomaron el modelo propuesto por la UNDRO (1979) y lo modificaron, en el primer caso eliminando la variable de exposición y en el segundo caso anexando el aspecto temporal; Cardona (2001) hace una evaluación holística del riesgo, tomando en cuenta la fragilidad socioeconómica y la falta de resiliencia del contexto; Davis (2004), en su modelo, incorpora la capacidad de adaptación, ya que el desarrollo de capacidades puede desempeñar un papel fundamental para minimizar la escala de los desastres; Jordaan (2006) propone un modelo para evaluar el riesgo de sequía agrícola considerando las características del peligro (probabilidad, severidad e intensidad) y tres tipos de vulnerabilidad (económica, social y ambiental); Ortega-Gaucin et al. (2018b) desarrollaron una metodología para determinar índices municipales de peligro, vulnerabilidad y riesgo por sequía, evaluando el peligro a partir de los registros históricos de sequía del Servicio Meteorológico Nacional (SMN) 
Tecnología y

Ciencias Agua
2022, Instituto Mexicano de Tecnología del Agua Open Access bajo la licencia CC BY-NC-SA 4.0 (https://creativecommons.org/licenses/by-nc$\mathrm{sa} / 4.0 /)$

y considerando cuatro tipos de vulnerabilidad (económica, social, ambiental y global), y Ortega-Gaucin et al. (2021) propusieron un método para calcular el riesgo por sequía agrícola considerando sus tres componentes esenciales: peligro, exposición y vulnerabilidad a la sequía. En la Tabla 9 se presentan las fórmulas de los modelos matemáticos referidos.

Tabla 9. Modelos matemáticos más usuales para calcular el riesgo.

\begin{tabular}{|c|c|c|}
\hline Autor & Fórmula & Descripción \\
\hline Yen (1971) & $R=1-P(X \leq x)^{n}$ & $\begin{array}{l}\text { Donde } P(X \leq x) \text { es la } \\
\text { probabilidad acumulada y } n \text { el } \\
\text { número de años, suponiendo } \\
\text { estacionariedad } \\
\text { independencia de los } \\
\text { acontecimientos extremos }\end{array}$ \\
\hline UNDRO (1979) & $R t=E \times R S=E \times(A \times V)$ & $\begin{array}{l}\text { Donde } R t \text { es el riesgo total; } E, \\
\text { la exposición; } R S, \text { el riesgo } \\
\text { específico; } A, \text { la amenaza; } V, \\
\text { la vulnerabilidad }\end{array}$ \\
\hline $\begin{array}{l}\text { Cardona } \\
\text { (1985) }\end{array}$ & $R i e=f(A i, V e)$ & $\begin{array}{l}\text { Donde } R i e \text { es el riesgo; } A_{i} \text { la } \\
\text { amenaza; } V_{e} \text {, la vulnerabilidad }\end{array}$ \\
\hline $\begin{array}{l}\text { Schneiderbauer } \\
\text { y Ehrlich } \\
(2004)\end{array}$ & $R_{a h d}=H_{a h d} x E_{a d} x V_{a h d}$ & $\begin{array}{l}\text { Donde } R_{\text {ahd }} \text { es el riesgo; } E \text {, la } \\
\text { exposición; } \quad V \text { la } \\
\text { vulnerabilidad; " } h " \text {, el tipo de }\end{array}$ \\
\hline
\end{tabular}


Teccnología y

Ciencias $\stackrel{\unlhd}{\unlhd}$ gua
2022, Instituto Mexicano de Tecnología del Agua Open Access bajo la licencia CC BY-NC-SA 4.0 (https://creativecommons.org/licenses/by-nc$\mathrm{sa} / 4.0 /$ )

\begin{tabular}{|c|c|c|}
\hline Autor & Fórmula & Descripción \\
\hline & & $\begin{array}{l}\text { peligro; "a", la región } \\
\text { geográfica afectada por el } \\
\text { peligro " } h " ; \text { "d", un día } \\
\text { determinado dentro del } \\
\text { periodo de tiempo durante el } \\
\text { cual se produce el desastre }\end{array}$ \\
\hline $\begin{array}{l}\text { Cardona } \\
(2001)\end{array}$ & $R_{T}=R_{F}(1+F)$ & $\begin{array}{l}\text { Donde } R_{T} \text { es el riesgo total; } R_{F} \\
\text { el riesgo físico, y } F \text { es un } \\
\text { coeficiente de agravamiento } \\
\text {-o de impacto- que depende } \\
\text { de la fragilidad socioeconómica } \\
F S \text { y de la falta de resiliencia } \\
\text { del contexto } F R\end{array}$ \\
\hline Davis (2004) & $R=\frac{V \times H}{C A}$ & $\begin{array}{l}\text { Donde } R \text { es el riesgo; } V \text {, la } \\
\text { vulnerabilidad, } H \text {, el peligro o } \\
\text { amenaza; } C A \text {, la capacidad de } \\
\text { adaptación }\end{array}$ \\
\hline Jordaan (2006) & $\begin{array}{l}R \\
=(H \\
\left./ C_{H}\right) \times\left|\frac{\sum\left(V_{e c o n} V_{e n v} V_{s o c}\right)}{\sum\left(C_{e c o n} C_{e n v} C_{s o c}\right)}\right|\end{array}$ & $\begin{array}{l}\text { Donde } H=f\left(H_{P} H s\right) \text {, con } H_{p} \text { es } \\
\text { la probabilidad de sequía con } \\
\text { una cierta magnitud } \\
\text { (severidad) que se produzca; } \\
H_{s} \text {, la severidad de la sequía } H ; \\
H_{s}=f(H i H d) ; H i \text { la intensidad } \\
\text { de la sequía; } H_{d} \text {, la duración de }\end{array}$ \\
\hline
\end{tabular}


Tecnología y

Ciencias $\stackrel{\unlhd}{\unlhd}$ gua
2022, Instituto Mexicano de Tecnología del Agua Open Access bajo la licencia CC BY-NC-SA 4.0 (https://creativecommons.org/licenses/by-nc$\mathrm{sa} / 4.0 /)$

\begin{tabular}{|c|c|c|}
\hline Autor & Fórmula & Descripción \\
\hline & & 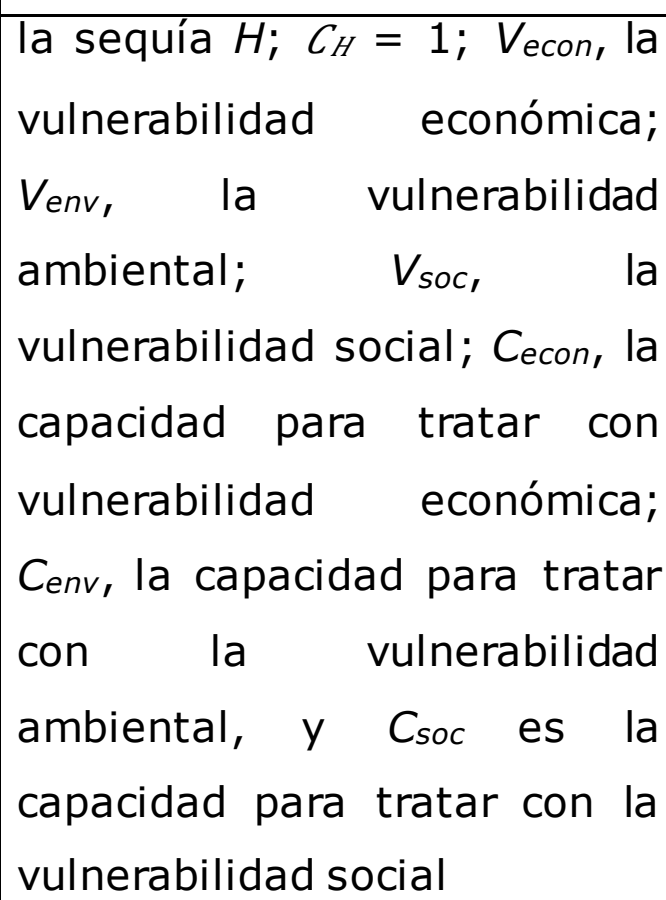 \\
\hline Burg (2008) & Riesgo $(R)=V+H$ & $\begin{array}{l}\text { Donde } V \text { es la vulnerabilidad } y \\
H \text { es peligro o amenaza }\end{array}$ \\
\hline $\begin{array}{l}\text { Ortega-Gaucin } \\
\text { et al. (2018b) }\end{array}$ & $I R=P x I V G$ & $\begin{array}{l}\text { Donde } I R \text { es el índice de riesgo } \\
\text { por sequía; } P \text {, la probabilidad } \\
\text { de ocurrencia de sequía } \\
\text { (peligro por sequía); e IVG es } \\
\text { el índice de vulnerabilidad } \\
\text { global ante la sequía (descrito } \\
\text { en la Tabla } 8 \text { ) }\end{array}$ \\
\hline $\begin{array}{l}\text { Ortega-Gaucin } \\
\text { et al. (2021) }\end{array}$ & $D R I=\frac{D H I+D E I+D V I}{3}$ & $\begin{array}{l}\text { Donde } D R I \text { es el índice de } \\
\text { riesgo por sequía agrícola; } \\
D H I \text {, el índice de peligro por }\end{array}$ \\
\hline
\end{tabular}


Teccnología y

Ciencias $\stackrel{\unlhd}{\unlhd}$ gua
2022, Instituto Mexicano de Tecnología del Agua Open Access bajo la licencia CC BY-NC-SA 4.0 (https://creativecommons.org/licenses/by-nc$\mathrm{sa} / 4.0 /)$

\begin{tabular}{|l|l|l|}
\hline Autor & \multicolumn{1}{|c|}{ Fórmula } & \multicolumn{1}{|c|}{ Descripción } \\
\hline & & $\begin{array}{l}\text { sequía; DEI, el índice de } \\
\text { exposición a la sequía, y DVI } \\
\text { es el índice de vulnerabilidad a } \\
\text { la sequía }\end{array}$ \\
\hline
\end{tabular}

Fuente: elaboración propia.

En términos generales, lo que se puede deducir de los modelos matemáticos descritos es que todos ellos utilizan las variables de peligro o amenaza, y vulnerabilidad como componentes esenciales del riesgo por sequía, incluyendo en algunos casos la exposición como variable independiente. En los últimos años, la fórmula matemática más comúnmente aceptada y utilizada es la que considera el riesgo como un producto del peligro (representado por la probabilidad de ocurrencia de sequía con cierto grado de severidad), la exposición y la vulnerabilidad (evaluadas mediante indicadores socioeconómicos y ambientales), tal como se puede observar en los trabajos de Carrao et al. (2016), Frischen et al. (2020) y Meza et al. (2020), entre otros. Ello está en consonancia con el concepto de riesgo propuesto por el IPCC (2014), que ha sido el más aceptado y difundido en la comunidad científica actual.

\section{Consideraciones}


Tecnología y

Ciencias $₫$ Agua
2022, Instituto Mexicano de Tecnología del Agua Open Access bajo la licencia CC BY-NC-SA 4.0 (https://creativecommons.org/licenses/by-nc$\mathrm{sa} / 4.0 /)$

Como se ha visto en este trabajo, hoy día existe una amplia gama de enfoques, métodos y herramientas para determinar las componentes del riesgo por sequía. Aquí se han resumido los resultados de una amplia revisión de literatura que ha sido generada en distintas partes del mundo. El hecho de revisar y recopilar los distintos métodos de forma sistemática puede servir para adaptar y mejorar la eficacia de las evaluaciones realizadas. Aunque existe una gran diversidad de enfoques y opciones metodológicas, lo cierto es que no hay métodos que sean universalmente aplicables para hacer estas evaluaciones, pues el fenómeno de la sequía depende de muchos factores contextuales y sus efectos son distintos en cada caso.

De acuerdo con la Convención de las Naciones Unidas para el Combate de la Desertificación (UNCCD), la Organización de las Naciones Unidas para la Alimentación y la Agricultura (FAO), la Asociación Mundial para el Agua (GWP), y la Organización Meteorológica Mundial (WMO), para mejorar las evaluaciones de la vulnerabilidad y el riesgo ante la sequía, los tomadores de decisiones y los responsables de formular políticas públicas pueden tomar en cuenta los siguientes aspectos (UNCCD/FAO/GWP/WMO, 2019):

- Adoptar un enfoque proactivo para realizar las evaluaciones antes de que se presenten las crisis por sequía. 
Tecnología y

Ciencias $\stackrel{\mho}{\varpi}$ Aua
2022, Instituto Mexicano de Tecnología del Agua Open Access bajo la licencia CC BY-NC-SA 4.0 (https://creativecommons.org/licenses/by-nc$\mathrm{sa} / 4.0 /)$

- Reconocer que la sequía es a menudo un fenómeno recurrente que interactúa con otras amenazas, y puede verse exacerbado por los patrones de gestión de recursos hídricos y terrestres.

- Utilizar los métodos de evaluación disponibles para fomentar enfoques inclusivos, intersectoriales y de múltiples escalas para la evaluación de la vulnerabilidad, y el riesgo a nivel comunitario y de cuenca.

- Aprender a partir de prueba/error, y revisar según las experiencias de otros, qué métodos son los más adecuados para fomentar la participación en las evaluaciones de vulnerabilidad de diferentes grupos sociales.

- Analizar dónde y cómo se deben recopilar, analizar y proteger los datos dispersos.

- Documentar los éxitos y fracasos de las evaluaciones, incluidos los casos en que los impactos de la sequía fueron más o menos graves de lo previsto en las condiciones climáticas prevalecientes.

- Aprender de las experiencias de los demás participando en un intercambio internacional coordinado de conocimientos, y abogar por el uso de estos procesos, incluida la revisión, validación, documentación y difusión.

Anticipar los resultados de un evento que aún no ha sucedido puede resultar difícil, pero en muchas regiones afectadas por la sequía ya se conocen muy bien sus efectos. En estas áreas, las estimaciones de vulnerabilidad y riesgo son procesos informales y continuos que forman parte de la cultura popular. La integración y 
Tecnología y

Ciencias $₫$ Agua
2022, Instituto Mexicano de Tecnología del Agua Open Access bajo la licencia CC BY-NC-SA 4.0 (https://creativecommons.org/licenses/by-nc$\mathrm{sa} / 4.0 /)$

coordinación de tales estimaciones informales con procesos colectivos de evaluaciones formales y bien documentadas que involucren a organizaciones de la sociedad civil, gobiernos locales, federales y otras instituciones pueden crear un entendimiento compartido más amplio, además de que ofrecen una base más prometedora para compartir y gestionar el riesgo a todos los niveles.

\section{Conclusiones}

La reducción del riesgo de sequía y sus impactos directos e indirectos asociados se ha convertido en una prioridad mundial, como lo muestra el número cada vez mayor de enfoques, métodos y herramientas de evaluación que se han publicado en las últimas décadas. Los esfuerzos por reducir los impactos de la sequía deben basarse en una comprensión sólida, y una caracterización fiable del fenómeno que conduzca a evaluaciones precisas para la toma de decisiones y la implementación de políticas públicas orientadas a ese objetivo. Sin embargo, aunque se han realizado grandes avances en los últimos años en términos de desarrollar mejores métodos y herramientas para caracterizar los componentes individuales del riesgo, aún queda mucho por hacer en ese sentido. La 
Tecnología y

Ciencias $₫$ Agua
2022, Instituto Mexicano de Tecnología del Agua

Open Access bajo la licencia CC BY-NC-SA 4.0 (https://creativecommons.org/licenses/by-nc$\mathrm{sa} / 4.0 /)$

revisión realizada en este trabajo ha mostrado que existe una gran diversidad de conceptos y métodos para este propósito, ninguno de los cuales es aplicable a todas las circunstancias, pues cada contexto específico requiere determinar cuál es el más apropiado en función del enfoque adoptado, la información disponible y el objetivo de la evaluación. Con la información que se proporciona en este artículo, los investigadores o evaluadores disponen de un panorama general que, en un momento dado, les puede servir de base para hacer un examen cuidadoso de cada uno de estos puntos, y elegir el marco teórico y el método que mejor se ajuste al contexto de su estudio o, en su defecto, para desarrollar o adaptar su propia propuesta conceptual y metodológica.

Es importante resaltar que, independientemente de los conceptos o modelos matemáticos que se adopten para evaluar el riesgo por sequía y sus componentes, la atención de los efectos causados por el fenómeno debe basarse en un enfoque proactivo de gestión del riesgo, es decir, en la planeación y diseño de estrategias (medidas estructurales y no estructurales sobre una base continua) que se pondrán en marcha con antelación a la ocurrencia de una sequía para prevenir y mitigar el nivel de exposición al riesgo y, por lo tanto, la vulnerabilidad a los impactos.

\section{Agradecimientos}

Este artículo se realizó con el apoyo del Consejo Nacional de Ciencia y Tecnología (Conacyt), en el marco del proyecto de investigación PDCPN- 
Teçnología y

Ciencias $₫$ Agua
2022, Instituto Mexicano de Tecnología del Agua Open Access bajo la licencia CC BY-NC-SA 4.0 (https://creativecommons.org/licenses/by-nc$\mathrm{sa} / 4.0 /)$

2017/4924 del Programa de Proyectos de Desarrollo Científico para atender Problemas Nacionales. Agradecemos los comentarios y sugerencias de dos revisores anónimos que permitieron mejorar el artículo.

\section{Referencias}

Adger, W. N. (2006). Vulnerability. Global Environmental Change, 16, 268-281. Recuperado de https://doi.org/10.1016/j.gloenvcha.2006.02.006

Adepetu, A. A., \& Berthe, A. (2007). Vulnerability of rural Sahelian households to drought: Options for adaptation. A Final Report. Submitted to Assessments of Impacts and Adaptations to Climate Change (AIACC), Proj. No. AF 9. Washington, DC, USA: The International START Secretariat.

Ahmadalipour, A., Moradkhani, H., Castelletti, A. , \& Magliocca, N. (2019). Future drought risk in Africa: Integrating vulnerability, climate change, and population growth. Science of the Total Environment 662, 672-686. Recuperado de https://doi.org/10.1016/j.scitotenv.2019.01.278

Anderson, M. B. (1994). Vulnerability to disaster and sustainable development: A general framework for assessing vulnerability. In: Munasinghe, M., \& Clarke, C. (eds.). Disaster prevention for sustainable development: Economic and policy issues. A Report from the Yokohama World Conference on Natural Disaster Reduction. May 23-27. Washington, DC, USA: World Bank.

Antwi-Agyei, P., Fraser, E. D., Dougill, A. J., Stringer, L. C., \& Simelton, E. (2012). Mapping the vulnerability of crop production to drought in 
Tecnología y

Ciencias Agua
2022, Instituto Mexicano de Tecnología del Agua Open Access bajo la licencia CC BY-NC-SA 4.0 (https://creativecommons.org/licenses/by-nc$\mathrm{sa} / 4.0 /)$

Ghana using rainfall, yield and socioeconomic data. Applied Geography, 32(2), 324-334. Recuperado de https://doi.org/10.1016/j.apgeog.2011.06.010

Ardabili, S., Mosavi, A., Dehghani, M., \& Varkonyi-Koczy, A. R. (2019). A deep learning and machine learning in hydrological processes climate change and earth systems a systematic review. Preprints. Recuperado de https://doi.org/10.20944/preprints201908.0166.v1

Barakat, F., \& Handoufe, A. (1998). Approche agroclimatique de la sécheresse agricole au Maroc. Science et changements planétaires / Sécheresse, 9(3), 201-208.

Bergaoui, M., \& Alouini, A. (2001). Caractérisation de la sécheresse météorologique et hydrologique: cas du Bassin Versant de Siliana en Tunisie. Science et Changements Planétaires / Sécheresse, 12(4), 205-213.

Bergman, K. H., Sabol, P., \& Miskus, D. (1988). Experimental indices for monitoring global drought conditions. In: Proceedings of $13^{\text {th }}$ Annual Climate Diagnostics Workshop. Cambridge, USA: United States Department of Commerce.

Bhuiyan, C. (2004). Various drought indices for monitoring drought condition in Aravalli Terrain of India. Proceedings of the $X X^{\text {th }}$ ISPRS Conference. Istanbul, Turkey: International Society for Photogrammetry and Remote Sensing. Recuperado de http://www.isprs.org/proceedings/XXXV/congress/comm7/papers/2 43.pdf 
Tecnología y

Ciencias $\stackrel{\unlhd}{\unlhd}$ gua
2022, Instituto Mexicano de Tecnología del Agua Open Access bajo la licencia CC BY-NC-SA 4.0 (https://creativecommons.org/licenses/by-nc$\mathrm{sa} / 4.0 /$ )

BID, Banco Interamericano de Desarrollo. (2003). Programa de información e indicadores de gestión de riesgos. Manizales, Colombia: Banco Interamericano de Desarrollo .

Birkmann, J. (2007). Risk and vulnerability indicators at different scales: applicability, usefulness and policy implications. Environmental Hazards, 7, 20-31. Recuperado de https://doi.org/10.1016/j.envhaz.2007.04.002

Blaikie, P., Cannon, T., Davis, I., \& Wisner, B. (1994). At risk: Natural hazards, people vulnerability, and disasters. London, UK, and New York, USA: Routledge Publishers.

Bohle, H. G., Downing, T. E., \& Watts, M. J. (1994).Climate change and social vulnerability. Toward a sociology and geography of food insecurity. Global Environmental Change, 4(1), 37-48. Recuperado de https://doi.org/10.1016/0959-3780(94)90020-5

Boken, V. K. (2005). Agricultural drought and its monitoring and prediction: some concepts (vol. 472). New York, USA: Oxford University Press.

Bouroncle, C., Rodríguez, C., Florián, M., Naswa, P., Lærke, S., \& Olhoff, A. (2016). Sistema Nacional de Indicadores de Adaptación al Cambio Climático (SIACC): definición del conjunto de indicadores. Bogotá: Centro Agronómico Tropical de Investigación y Enseñanza (CATIE).

Bootsma, A., Boisvert, J., \& Baier, R. (1996). La sécheresse et I'agriculture canadienne: une revue des moyens d'action. Science et changements planétaires / Sécheresse, 7(4), 277-285.

Brooks, N. (2003). Vulnerability, risk and adaptation: A conceptual framework. Tyndall Centre for Climate Change Research Working 
Tecnología y

Ciencias $\widetilde{\Xi}$ Agua
2022, Instituto Mexicano de Tecnología del Agua Open Access bajo la licencia CC BY-NC-SA 4.0 (https://creativecommons.org/licenses/by-nc$\mathrm{sa} / 4.0 /)$

Paper, 38(38), 1-16. Recuperado de https://www.researchgate.net/publication/200032746_Vulnerability _Risk_and_Adaptation_A_Conceptual_Framework

Burg, J. (2008). Measuring populations' vulnerabilities for famine and food security interventions: The case of Ethiopia's chronic vulnerability index. Disasters, 32(4), 609-630. Recuperado de https://doi.org/10.1111/j.1467-7717.2008.01057.x

Burton, I., Kates, R. W., \& White, G. F. (1978). The environment as hazard. New York, USA: Oxford University Press.

Byun, H. R., \& Wilhite, D. A. (1999). Objective quantification of drought severity and duration. Journal of Climate, 12(9), 2747-2756. Recuperado de https://doi.org/10.1175/15200442(1999)012<2747:OQODSA>2.0.CO;2

Cardona, O. (2005). Indicadores de riesgo de desastre y de gestión de riesgos. Informe resumido. BID/IDEA programa de indicadores para la gestión del riesgo de desastres. Washington, DC, USA: Banco Interamericano de Desarrollo. Recuperado de https://www.cepal.org/ilpes/noticias/paginas/0/35060/INDICADOR ES_DE_RIESGO_DE_DESASTRES_BID.pdf

Cardona, O. (2001). Estimación holística del riesgo sísmico utilizando sistemas dinámicos complejos (tesis doctoral). Barcelona. España: Universitat Politècnica de Catalunya. Recuperado de https://repositorio.gestiondelriesgo.gov.co/bitstream/handle/20.50 0.11762/19751/HolisticaRiesgoSismicoBogota(Cardona_2001).pdf? sequence $=1$ 
Tecnología y

Ciencias $₫$ Agua
2022, Instituto Mexicano de Tecnología del Agua Open Access bajo la licencia CC BY-NC-SA 4.0 (https://creativecommons.org/licenses/by-nc$\mathrm{sa} / 4.0 /)$

Cardona, O. (1993). Evaluación de la amenaza la vulnerabilidad y el riesgo. Elementos para el ordenamiento y la planeación del desarrollo. En: Maskrey, A. (comp.). Los desastres no son naturales (pp. 51-74). Ciudad de Panamá, Panamá: La Red.

Cardona, O. D. (1985). Hazard, vulnerability and risk assessment. Unedited working paper. Skopje, Yugoslavia: Institute of Earthqua ke Engineering and Engineering Seismology.

Carrao, H., Naumann, G., \& Barbosa, P. (2016). Mapping global pattems of drought risk: An empirical framework based on sub-national estimates of hazard, exposure and vulnerability. Global Environmental Change, 39, 108-124. Recuperado de https://doi.org/10.1016/j.gloenvcha.2016.04.012

Carter, M. R., Little, P. D., Mogues, T., \& Negatu, W. (2007). Poverty traps and natural disasters in Ethiopia and Honduras. World Development, $35(5)$, 835-856. Recuperado de https://doi.org/10.1016/j.worlddev.2006.09.010

Chambers, R. (1989). Editorial introduction: Vulnerability, coping and policy. Institute of Development Study IDS Bulletin, 20(2), 1-7. Recuperado de https://opendocs.ids.ac.uk/opendocs/bitstream/handle/20.500.124 13/9551/IDSB_20_2_10.1111-j.1759-

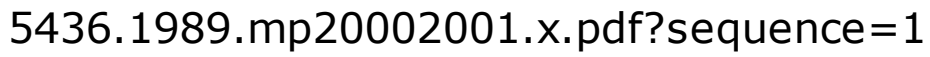

Chandrasekar, K., Sai, M. S., Roy, P., Jayaraman, V., \& Krishnamoorthy, R. (2009). Identification of agricultural drought vulnerable areas of Tamil Nadu, India using GIS-based multi criteria analysis. Asian 
Teçnología y

Ciencias $\approx$ Agua
2022, Instituto Mexicano de Tecnología del Agua Open Access bajo la licencia CC BY-NC-SA 4.0 (https://creativecommons.org/licenses/by-nc$\mathrm{sa} / 4.0 /$ )

Journal of Environment and Disaster Management, 1(1), 40-61. Recuperado de https://doi.org/10.3850/S17939240200900009X

Cheng, J., \& Tao, J. P. (2010). Fuzzy comprehensive evaluation of drought vulnerability based on the analytic hierarchy process: An empirical study from Xiaogan city in Hubei province. Agriculture and Agricultural Science Procedia, 1, 126-135. Recuperado de https://doi.org/10.1016/j.aaspro.2010.09.015

Cole, S., Gine, X., Tobacman, J., Topalova, P., Townsend, R., \& Vickery, J. (2013). Barriers to household risk management: Evidence from India. American Economic Journal: Applied Economics, 5(1), 104135. Recuperado de https://doi.org/10.1257/app.5.1.104

Correia, F. N., Santos, M. A., \& Rodrigues, R. R. (1991). Reliability in regional drought studies. In: Ganoulis J. (ed.). Water resources engineering risk assessment (pp. 43-62). Vol. G 29. Berlin, Germany: NATO ASI Series.

Cutter, S. L., Boruff, B. J., \& Shirley, W. L. (2003). Social vulnerability to environmental hazards. Social Sciences Quarterly, 84(2), 243-261. Recuperado de https://doi.org/10.1111/1540-6237.8402002

Davis, I. (2004). Progress in analysis of social vulnerability and capacity. In: Bankoff, G., Frerks, G., \& Hilhorst, D. (eds.). Mapping vulnerability: Disasters, development and people. London, UK: Earth Scan.

Deems, H. J. (2010). Vulnerability of rural communities in the Mediterranean region to climate change and water scarcity: The case of Cyprus (Master thesis). Barcelona, España: Universitat de 
Teçnología y

Ciencias $\widetilde{\Xi}$ Agua
2022, Instituto Mexicano de Tecnología del Agua Open Access bajo la licencia CC BY-NC-SA 4.0 (https://creativecommons.org/licenses/by-nc$\mathrm{sa} / 4.0 /)$

Barcelona.

Recuperado

de https://www.cyi.ac.cy/images/projects/eewrc/clico/Deems_Rural_V ulnerability_Cyprus_thesis_Sep2010.pdf

Deo, R. C. \& Şahin, M. (2015). Application of the extreme learning machine algorithm for the prediction of monthly Effective Drought Index in eastern Australia. Atmospheric Research, 153, 512-525. Recuperado de http://dx.doi.org/10.1016/j.atmosres.2014.10.016

Deressa, T., Hassan, R. M., \& Ringler, C. (2008). Measuring Ethiopian farmers' vulnerability to climate change across regional states. Food Policy, Serie 806. Washington, DC, USA: International Food Policy Research Institute. Recuperado de http://www.ifpri.org/publication/measuring-ethiopian-farmersvulnerability-climate-change-across-regional-states

Dercon, S. (2004). Growth and shocks: Evidence from rural Ethiopia. Journal of Development Economics, 74(2), 309-329. Recuperado de Recuperado de https://doi.org/10.1016/j.jdeveco.2004.01.001

De-Stefano, L., González, I., Ballesteros, M., Urquijo, J., \& Blauhut, V. (2015). Methodological approach considering different factors influencing vulnerability - pan-European scale. Drought-R\&SPI Technical Rep. No. 26. Recuperado de https://www.researchgate.net/publication/274536771_METHODOL OGICAL_APPROACH_CONSIDERING_DIFFERENT_FACTORS_INFLUE NCING_VULNERABILITY_-_PAN-EUROPEAN_SCALE

Downing, T. E. (1991). Assessing socioeconomic vulnerability to famine: Frameworks, concepts, and applications. Final Report to the US 
Tecnología y

Ciencias $\approx$ Agua
2022, Instituto Mexicano de Tecnología del Agua Open Access bajo la licencia CC BY-NC-SA 4.0 (https://creativecommons.org/licenses/by-nc$\mathrm{sa} / 4.0 /)$

Agency for International Development, Famine Early Warning System Project. Recuperado de https://pdf.usaid.gov/pdf_docs/pnabj875.pdf

Downing, T. E., \& Bakker, K. (2000). Drought discourse and vulnerability. In: Wilhite, D. A. (ed.). Drought: A global assessment. Natural Hazards and Disasters Series. London, USA: Routledge Publishers.

Dracup, J. A., Lee, K. S., \& Paulson, J. R. (1980). On the statistical characteristics of drought events. Water Resources Research, 16(2), 289-296.

Elbers, C., Gunning, J. W., \& Kinsey, B. (2007). Growth and risk: Methodology and micro evidence. The World Bank Economic Review, 21(1), 1-20. Recuperado de https://doi.org/10.1093/wber//hl008

Feng, P., Wang, B., Liu, D. L., \& Yu, Q. (2019). Machine learning-based integration of remotely-sensed drought factors can improve the estimation of agricultural drought in South-Eastern Australia. Agricultural Systems, 173, 303-316. Recuperado de https://doi.org/10.1016/j.agsy.2019.03.015

Flörke, M., Wimmer, F., \& Laaser, C. (2011). Final Report for the Project Climate Adaptation - modelling waterscenarios and sectoral impacts. Contract $N^{\circ}$ DG ENV.D.2/SER/2009/0034. Center for Environmental Systems Research, Kassel. Recuperado de https://op.europa.eu/en/publication-detail/-/publication/ff6cb987cdeb-483c-b569-b657111f504a/language-en

Fontaine, M., \& Steinemann, A. C. (2009). Assessing vulnerability to natural hazards: An impact-based method and application to drought 
Tecnología y

Ciencias $₫$ Agua
2022, Instituto Mexicano de Tecnología del Agua Open Access bajo la licencia CC BY-NC-SA 4.0 (https://creativecommons.org/licenses/by-nc$\mathrm{sa} / 4.0 /)$

in Washington State. Natural Hazards Review, 10(1), 11-18. Recuperado de https://cig.uw.edu/publications/assessingvulnerability-to-natural-hazards-an-impact-based-method-andapplication-to-drought-in-washington-state/

Frischen, J., Meza, I., Rupp, D., Wietler, K., \& Hagenlocher, M. (2020). Drought risk to agricultural systems in Zimbabwe: A spatial analysis of hazard, exposure, and vulnerability. Sustainability, 12(3), 752. Recuperado de https://doi.org/10.3390/su12030752

Füssel, H.-M. (2005). Vulnerability in climate change research: $A$ Comprehensive conceptual framework. Recuperado de https://escholarship.org/content/qt8993z6nm/qt8993z6nm.pdf

Füssel, H.-M. (2004). Coevolution of the political and conceptual frameworks for climate change vulnerability assessments. In: Proceedings of the 2002 Berlin Conference on the Human Dimensions of Global Environmental Change Knowledge for the Sustainability Transition.The Challenge for Social Science (pp. 302-320). Amsterdam, Berlin, Potsdam and Oldenburg Global Governance Project.

Gibbs, W. J., Maher, J. V., \& John, V. (1967). Rainfall deciles as drought indicators. In: Bulletin (Commonwealth Bureau of Meteorology (Australia)). No. 48 (p. 84). Melbourne, Australia: Bureau of Meteorology.

González, T. I., Urquijo, J., Blauhut, V., Villarroya, F., \& De-Stefano, L. (2016). Learning from experience: A systematic review of assessments of vulnerability to drought. Natural Hazards, 80(2), 
Tecnología y

Ciencias $\approx$ Agua
2022, Instituto Mexicano de Tecnología del Agua Open Access bajo la licencia CC BY-NC-SA 4.0 (https://creativecommons.org/licenses/by-nc$\mathrm{sa} / 4.0 /)$

951-973. Recuperado de https://doi.org/10.1007/s11069-0152006-1

Gusyev, M. A., Hasegawa, A., Magome, J., Kuribayashi, D. H., \& Lee, S. (2015). Drought Assessment in the Pampanga River Basin, the Philippines. Part 1: A Role of Dam Infrastructure in Historical Droughts. Proceedings of the 21st International Congress on Modelling and Simulation (MODSIM 2015). Broadbeach, Queensland, Australia. DOI: 10.13140/RG.2.1.4931.4321

Guo, Y., Huang, S., Huang, Q., Wang, H., Wang, L., \& Fang, W. (2019). Copulas-based bivariate socioeconomic drought dynamic risk assessment in a changing environment. Journal of Hydrology, 575, 1052-1064. Recuperado de https://doi.org/10.1016/j.jhydrol.2019.06.010

Hagenlocher, M., Meza, I., Anderson, C. C., Min, A., Renaud, F. G., Walz, Y., Siebert, S., \& Sebesvari, Z. (2019). Drought vulnerability and risk assessments: State of the art, persistent gaps, and research agenda. Environmental Research Letters, 14(8), 083002. Recuperado de https://iopscience.iop.org/article/10.1088/1748-9326/ab225d/meta

Hayes, M., Svoboda, M., Wall, N., \& Widhalm, M. (2011).The Lincoln Declaration on Drought Indices: Universal meteorological drought index recommended. Bulletin of the American Meteorological Society, 92(4), 485-488.

Heim, Jr., R. R. (2002). A review of twentieth-century drought indices used in the United States. Bulletin of the American Meteorological Society, 83(8), 1149-1166. Recuperado de 
Teçnología y

Ciencias $₫$ Agua
2022, Instituto Mexicano de Tecnología del Agua Open Access bajo la licencia CC BY-NC-SA 4.0 (https://creativecommons.org/licenses/by-nc$\mathrm{sa} / 4.0 /$ )

https://journals.ametsoc.org/view/journals/bams/83/8/1520-047783_8_1149.xml

Hoddinott, J., \& Quisumbing, A. (2003). Methods for microeconometric risk and vulnerability assessment. In: Risk, shocks, and human development (pp. 62-100). London, UK: Palgrave Macmillan. Recuperado de https://doi.org/10.1057/9780230274129_4

Iglesias, A., Moneo, M., \& Quiroga, S. (2007). Methods for evaluating social vulnerability to drought (Part 1 . Components of drought planning. 1.3. Methodological component). In: Iglesias, A., Moneo, M., \& López-Francos, A. (eds.). Drought management guidelines technical annex. Zaragoza: CIHEAM / EC MEDA Water, 129-133. (Options Méditerranéennes: Série B. Etudes et Recherches; n. 58). Recuperado de http://om.ciheam.org/om/pdf/b58/00800538.pdf

IPCC, Grupo Intergubernamental de Expertos sobre el Cambio Climático. (2014). Cambio climático 2014. Impactos, adaptación y vulnerabilidad - Resumen para responsables de políticas. Contribución del Grupo de Trabajo II al Quinto Informe de Evaluación del Grupo Intergubernamental de Expertos sobre El Cambio Climático. Recuperado

de https://www.ipcc.ch/site/assets/uploads/2018/03/ar5_wgII_spm_e s-1.pdf

IPCC, Intergovernmental Panel on Climate Change. (2012). Managing the risks of extreme events and disasters to advance climate change adaptation. Field, C., Barros, V., Stocker, T., \& Dahe, Q. (eds.). Cambridge University Press. Recuperado de 
Tecnología y

Ciencias $\approx$ Agua
2022, Instituto Mexicano de Tecnología del Agua Open Access bajo la licencia CC BY-NC-SA 4.0 (https://creativecommons.org/licenses/by-nc$\mathrm{sa} / 4.0 /)$

https://archive.ipcc.ch/pdf/specialreports/srex/SREX_Full_Report.pdf

IPCC, Intergovernmental Panel on Climate Change. Climate Change. (2001). The Scientific Basis. Cambridge, UK; New York, USA: Cambridge University Press. Recuperado de http://webpages.icav.up.pt/PTDC/CVT/098487/2008/IPPC, \%20200 1.pdf

Jordaan, A. J. (2006). Disaster risk assessment: Thumb sucking or scientific risk quantification? Paper presented at Annual Congress: Disaster Management Institute of Southern Africa (DMISA) (pp. 112). Hartenbosch, South Africa.

Kaly, U., \& Pratt, C. (2000). Environmental vulnerability index: Development and provisional indices and profiles for Fiji, Samoa, Tuvalu and Vanuatu. Phase II report for NZODA. In: SOPAC Technical Report 306. (pp. 89). Suva, Fiji: SOPAC.

Kanbur, R. (1987). The standard of living: Uncertainty, inequality and opportunity. In: Hawtorn, G. (ed.). The standard of living. New York, USA: Cambridge University Press.

Kates, R. W. (1985). The interaction of climate and society. In: Kates, R. W., Ausubel, J. H., \& Berbarian, M. (eds.). Climate impacts assessment (pp. 3-36). Chichester, UK: John Wiley. Recuperado de http://www.rwkates.org/pdfs/a1985.01.pdf

Kogan, F. N. (1990). Remote sensing of weather impacts on vegetation in non-homogeneous areas. International Journal of Remote 
Teccnología y

Ciencias $₫$ Agua
2022, Instituto Mexicano de Tecnología del Agua Open Access bajo la licencia CC BY-NC-SA 4.0 (https://creativecommons.org/licenses/by-nc$\mathrm{sa} / 4.0 /)$

Sensing, 11(8), 1405-1419. Recuperado de https://doi.org/10.1080/01431169008955102

Kogan, F. N. (1995). Droughts of the late 1980s in the United States as derived from NOAA polar orbiting satellite data. Bulletin of the American Meteorology Society, 76(5), 655-668. Recuperado de https://doi.org/10.1175/1520-0477(1995)076<0655:DOTLIT>2.0.CO;2

Luers, A. L., Lobell, D. B., Sklar, L. S., Addams, C. L., \& Matson, P. A. (2003). Method for quantifying vulnerability, applied to the agricultural system of the Yaqui Valley, Mexico. Global Environmental Change, 13(4), 255-267. Recuperado de https://yaquivalley.stanford.edu/pdf/luers_GEC_2003.pdf

Magaña, V. (2013). Guía metodológica para la evaluación de la vulnerabilidad ante cambio climático. México, DF, México: Instituto Nacional de Ecología y Programa de las Naciones Unidas para el Desarrollo.

Marcos, O. (2001). Sequía: definiciones, tipología y métodos de cuantificación. Investigaciones Geográficas, 26, 59-80. Recuperado de http://rua.ua.es/dspace/handle/10045/363

Me-Bar, Y., \& Valdez, F, Jr. (2005). On the vulnerability of the ancient Maya society to natural threats. Journal of Archaeological Science, 32, 813-825. Recuperado de https://doi.org/10.1016/j.jas.2004.11.015

Meza, I., Siebert, S., Döll, P., Kusche, J., Herbert, C., Eyshi-Rezaei, E., Nouri, H., Gerdener, H., Popat, E., Frischen, J., Naumann, G., Vogt, J. V., Walz, Y., Sebesvari, Z., \& Hagenlocher, M. (2020). Global-scale 
Teçnología y

Ciencias $₫$ Agua
2022, Instituto Mexicano de Tecnología del Agua Open Access bajo la licencia CC BY-NC-SA 4.0 (https://creativecommons.org/licenses/by-nc$\mathrm{sa} / 4.0 /$ )

drought risk assessment for agricultural systems. Natural Hazards and Earth System Sciences, 20(2), 695-712. Recuperado de https://doi.org/10.5194/nhess-20-695-2020

Mckee, T. B., Doesken, N. J., \& Kleist, J. (1993). The relationship of drought frequency and duration to time scales. AMS 8th Conference on Applied Climatology, 17(22), 179-184. Recuperado de https://doi.org/citeulike-article-id:10490403

Mishra, A., \& Singh, V. P. (2010). A review of drought concepts. Journal of Hydrology, 391(1-2), 202-216. Recuperado de https://doi.org/10.1016/j.jhydrol.2010.07.012

Modarres, R. (2007). Streamflow drought time series forecasting. Stochastic Environmental Research and Risk Assessment, 21(3), 223-233.

Nalbantis, I., \& Tsakiris, G. (2008). Assessment of hydrological drought revisited. Water Resources Management, 23(5), 881-897.

Naumann, G., Barbosa, P., Garrote, L., Iglesias, A., \& Vogt, J. (2013). Exploring drought vulnerability in Africa: An indicator-based analysis to inform early warning systems. Hydrology and Earth System Sciences Discussions, 10(10), 12217-12254. DOI: 10.5194/hess-181591-2014

Narasimhan, B., \& Srinivasan, R. (2005). Development and evaluation of Soil Moisture Deficit Index (SMDI) and Evapotranspiration Deficit Index (ETDI) for agricultural drought monitoring. Agricultural and Forest Meteorology, 133(1), 69-88. Recuperado de https://doi.org/10.1016/j.agrformet.2005.07.012 
Tecnología y

Ciencias $₫$ Agua
2022, Instituto Mexicano de Tecnología del Agua Open Access bajo la licencia CC BY-NC-SA 4.0 (https://creativecommons.org/licenses/by-nc$\mathrm{sa} / 4.0 /)$

NDMC, National Drought Mitigation Center. (1995). Understanding the drought phenomenon: The role of definitions. Lincoln, USA: National Drought Mitigation Center.

OMM \& GWP, Organización Meteorológica Mundial y Asociación Mundial para el Agua. (2006). Vigilancia y alerta temprana de la sequía: conceptos, progresos y desafíos futuros. Ginebra, Suiza. Organización Meteorológica Mundial y Asociación Mundial para el Agua.

Recuperado

de https://www.droughtmanagement.info/literature/WMO_drought_m onitoring_early_warning_es_2006.pdf

OMM \& GWP, Organización Meteorológica Mundial y Asociación Mundial para el Agua. (2016). Manual de indicadores e índices de sequía. Programa de Gestión Integrada de Sequías. Recuperado de http://www.droughtmanagement.info/literature/WMO-GWP_Manual-de-indicadores_2016

Ortega-Gaucin, D. (2012a). Drought in Nuevo León: Vulnerability, impacts, and mitigation strategies. Monterrey, México: Instituto del Agua del Estado de Nuevo León. Recuperado de https://agua.org.mx/biblioteca/sequia-en-nuevo-leonvulnerabilidad-impactos-y-estrategias-de-mitigacion/

Ortega-Gaucin, D. (2012b). Impacto socio-económico de la sequía en un distrito de riego: estrategias para mitigarlo. Saarbrücken, Alemania: Editorial Académica Española.

Ortega-Gaucin, D., Ceballos-Tavares, J. A., Ordoñez, A., \& CastellanoBahena, H. V. (2021). Agricultural drought risk assessment: A spatial analysis of hazard, exposure, and vulnerability in Zacatecas, Mexico. 
Teccnología y

Ciencias $₫$ Agua
2022, Instituto Mexicano de Tecnología del Agua Open Access bajo la licencia CC BY-NC-SA 4.0 (https://creativecommons.org/licenses/by-nc$\mathrm{sa} / 4.0 /)$

Water, 13(10)，

1431.

Recuperado

de

https://doi.org/10.3390/w13101431

Ortega-Gaucin, D., De-la-Cruz-Bartolón, J., \& Castellano-Bahena, H. V. (2018a). Drought Vulnerability Indices in Mexico. Water, 10 (11), 1671. MDPI AG. Recuperado de https://doi.org/10.3390/w10111671 Ortega-Gaucin, D., De-la-Cruz-Bartolón, J., \& Castellano-Bahena, H. V. (2018b). Hazard, vulnerability, and risk due to drought in the context of climate change in Mexico. In: Water and climate change (pp. 80105). Jiutepec, México: Instituto Mexicano de Tecnología del Agua. Recuperado de http://repositorio.imta.mx/handle/20.500.12013/2192

Ortega-Gaucin, D., López, M., \& Arreguín, F. I. (2016). Drought risk management in Mexico: Progress and challenges. International Journal of Safety and Security Engineering, 6(2), 161-170. Recuperado de https://doi.org/10.2495/SAFE-V6-N2-161-170

Ortega-Gaucin, D., \& Velasco, I. (2015). Program of preventive and mitigation measures in the Río Balsas Basin Council, Mexico. In: Andreu, J., Solera, A., Paredes-Arquiola, J., Haro-Monteagudo, D., \& Van-Lanen, H. (eds.). Drought: Research and science-policy interfacing (pp. 493-498). The Netherlands: CRC Press/Balkema. Recuperado de https://www.researchgate.net/publication/275963665_Program_of _Preventive_and_Mitigation_Drought_Measures_in_the_Rio_Balsa s_Basin_Council_Mexico 
Tecnología y

Ciencias $₫$ Agua
2022, Instituto Mexicano de Tecnología del Agua Open Access bajo la licencia CC BY-NC-SA 4.0 (https://creativecommons.org/licenses/by-nc$\mathrm{sa} / 4.0 /)$

Palmer, W. C. (1968). Keeping track of crop moisture conditions, nationwide: The new crop moisture index. Weatherwise, 21(4), 156161. DOI: $10.1080 / 00431672.1968 .9932814$

Palmer, W. C. (1965). Meteorological drought. Weather Bureau Research Paper No. 45. Washington, DC, USA: US Department of Commerce. Recuperado de https://www.droughtmanagement.info/literature/USWB_Meteorolog ical_Drought_1965.pdf

Park, S., Im, J., Jang, E., \& Rhee, J. (2015). Drought assessment and monitoring through blending of multi-sensor indices using machine learning approaches for different climate regions. Agricultural and Forest Meteorology, 216, 157-169. Recuperado de http://dx.doi.org/10.1016/j.agrformet.2015.10.011

Patrick, E. (2003). Sequía: vulnerabilidad y crisis en las tierras áridas. New York, USA: Programa de las Naciones Unidas para el Desarrollo (PNUD).

Peduzzi, P., Dao, H., Herold, C., \& Mouton, F. (2009). Assessing global exposure and vulnerability towards natural hazards: The Disaster Risk Index. Natural Hazards and Earth System Sciences, 9, 11491159.

Recuperado

de https://nhess.copernicus.org/articles/9/1149/2009/nhess-9-11492009.pdf

Rhee, J., \& Im, J. (2017). Meteorological drought forecasting for ungauged areas based on machine learning: Using long-range climate forecast and remote sensing data. Agricultural and Forest 
Tecnología y

Ciencias $\stackrel{\Xi}{\Im}$ Aua
2022, Instituto Mexicano de Tecnología del Agua Open Access bajo la licencia CC BY-NC-SA 4.0 (https://creativecommons.org/licenses/by-nc$\mathrm{sa} / 4.0 /)$

Meteorology, 237, 105-122. Recuperado de https://doi.org/10.1016/j.agrformet.2017.02.011

Safavi, H. R., Esfahani, M. K., \& Zamani, A. R. (2014). Integrated index for assessment of vulnerability to drought, case study: Zayandehrood River Basin, Iran. Water Resources Management, 28(6), 1671-1688. Recuperado de https://doi.org/10.1007/s11269014-0576-4

Shafer, B., \& Dezman, L. (1982). Development of a Surface WaterSupply Index (SWSI) to assess the severity of drought conditions in Snowpack Runoff Areas. In: Proceedings of the Western Snow Conference (pp. 164-175). Recuperado de https://westernsnowconference.org/sites/westernsnowconference.o rg/PDFs/1982Shafer.pdf

Sisto, N., Guajardo-Quiroga, R., \& Aguilar-Barajas, I. (2011). Estimación de los impactos económicos de una sequía. Tecnología y Ciencias del Agua, 2(2), 111-123. Recuperado de http://www.scielo.org.mx/scielo.php?script=sci_arttext\&pid=S2007 $-24222011000200008 \&$ Ing $=e s \& t$ lng $=e s$

Schneiderbauer, S., \& Ehrlich, D. (2004). Risk, hazard, and people's vulnerability to natural hazards: A review of definitions, concepts and data. European Commission Joint Research Centre, EUR, 21410, 40. Recuperado de https://www.researchgate.net/publication/268149143_Risk_Hazard _and_People's_Vulnerability_to_Natural_Hazards_a_Review_of_Defi nitions_Concepts_and_Data 
Tecnología y

Ciencias $₫$ Agua
2022, Instituto Mexicano de Tecnología del Agua Open Access bajo la licencia CC BY-NC-SA 4.0 (https://creativecommons.org/licenses/by-nc$\mathrm{sa} / 4.0 /)$

Schuschny, A., \& Soto, H. (2009). Guía metodológica, diseño de indicadores compuestos de desarrollo sostenible. Santiago de Chile, Chile: CEPAL, Naciones Unidas. Recuperado de https://www.cepal.org/es/publicaciones/3661-guia-metodologicadiseno-indicadores-compuestos-desarrollo-sostenible

Tate, E. L., \& Gustard, A. (2000). Drought definition: A hydrological perspective. In: Voght J. V., \& Somma, F. (eds.). Drought and drought mitigation in Europe (advances in natural and technological hazard research). Vol 14. Dordrecht, The Netherlands: Springer. Recuperado de https://doi.org/10.1007/978-94-015-9472-1_3

Tarpley, J. D., Schneider, S. R., \& Money, R. L. (1984). Global vegetation indices from the NOAA7 meteorological satellite. Journal of Climate and Applied Meteorology, 23(3), 491-494. Recuperado de https://doi.org/10.1175/15200450(1984)023<0491:GVIFTN>2.0.CO;2

Tsakiris, G. (2007). Practical application of risk and hazard concepts in proactive planning. European Water, 19(20), 47-56. Recuperado de https://www.ewra.net/ew/pdf/EW_2007_19-20_05.pdf

Tsakiris, G., Nalbantis, I., Vangelis, H., Verbeiren, B., Huysmans, M., Tychon, B., \& Batelaan, O. (2013). A System-based paradigm of drought analysis for operational management. Water Resources Management, 27(15), 5281-5297. Recuperado de https://doi.org/10.1007/s11269-013-0471-4 
Tecnología y

Ciencias $₫$ Agua
2022, Instituto Mexicano de Tecnología del Agua Open Access bajo la licencia CC BY-NC-SA 4.0 (https://creativecommons.org/licenses/by-nc$\mathrm{sa} / 4.0 /)$

Timmerman, P. (1981). Vulnerability, resilience, and the collapse of society. In: Environmental Monograph, No. 1. Toronto, Canada: Institute for Environmental Studies, University of Toronto.

UNCCD, FAO, GWP, \& WMO, Convención de las Naciones Unidas para el Combate de la Desertificación, Organización de las Naciones Unidas para la Alimentación y la Agricultura, \& Asociación Mundial para el Agua y Organización Meteorológica Mundial. (2019). Drought impact and vulnerability assessment: Available approaches and policy recommendations. UNCCD. Recuperado de https://www.unccd.int/publications

UNISDR, Estrategia Internacional para la Reducción de Desastres. (2009). En: Terminología sobre reducción del riesgo de desastres, 43. Recuperado de http://www.unisdr.org/files/7817_UNISDRTerminologySpanish.pdf

UNDRO, United Nations Disaster Relief Organization. (1979). Natural disasters and vulnerability analysis. Report of Experts Group Meeting. Geneva, Switzerland: UN, United Nations Disaster Relief Organization.

Valiente, M. (2001). Sequía: definiciones, tipologías y métodos de cuantificación. Investigaciones Geográficas (España), (26), 59-80. Universidad de Alicante Alicante, España. Recuperado de https://www.redalyc.org/pdf/176/Resumenes/Resumen_17602604 $\_1 . p d f$

Van-Rooy, M. P. (1965). A rainfall anomaly index (RAI) independent of time and space. Notos, 14, 43-48. 
Tecnología y

Ciencias $\stackrel{\unlhd}{\unlhd}$ gua
2022, Instituto Mexicano de Tecnología del Agua Open Access bajo la licencia CC BY-NC-SA 4.0 (https://creativecommons.org/licenses/by-nc$\mathrm{sa} / 4.0 /)$

Velasco, I. (2002). Plan de preparación para afrontar sequías en un distrito de riego (tesis de Doctorado en Ingeniería Hidráulica). Universidad Nacional Autónoma de México, México.

Velasco, I., Ochoa, L., \& Gutiérrez, C. (2005). Sequía, un problema de perspectiva y gestión. Región y Sociedad, 17(34), 35-71. Recuperado

de http://www.scielo.org.mx/scielo.php?script=sci_arttext\&pid=S1870 $-39252005000300002 \& \operatorname{lng}=e s \&$ tlng $=e s$

Vicente-Serrano, S. M., Beguería, S., \& López-Moreno, J. I. (2010). A multiscalar drought index sensitive to global warming: The standardized precipitation evapotranspiration index. Journal of Climate, 23(7), 1696-1718. Recuperado de https://doi.org/10.1175/2009JCLI2909.1

Wanders, N., Van-Lanen, H. A. J., \& Van-Loon, A. F. (2010). WATCH Technical Report No. 24: Indicators for drought characterization on a global scale. Recuperado de https://library.wur.nl/WebQuery/wurpubs/fulltext/160049

Webb, P., \& Harinarayan, A. (1999). A measure of uncertainty: The nature of vulnerability and its relationship to malnutrition. Disasters, 23(4), 292-305.

Welle, T., \& Birkmann, J. (2015). The World Risk Index - An Approach to assess risk and vulnerability on a global scale. Journal of Extreme Events, 2(1), $1550003 . \quad$ Recuperado de https://doi.org/10.1142/S2345737615500037 
Tecnología y

Ciencias $₫$ Agua
2022, Instituto Mexicano de Tecnología del Agua Open Access bajo la licencia CC BY-NC-SA 4.0 (https://creativecommons.org/licenses/by-nc$\mathrm{sa} / 4.0 /)$

Wilhite, D. A. (ed.). (2005). Drought and water crises: Science, technology, and management issues. Boca Raton, USA: Taylor \& Francis, CRC Press.

Wilhite, D. A. (2000). Chapter 1 Drought as a natural hazard: Concepts and definitions. In: Wilhite, D. (ed.). Drought: A global assessment. (pp. 3-18). London, England: Routledge. Recuperado de http://digitalcommons.unl.edu/droughtfacpub/69

Wilhite, D. A., \& Glantz, M. H. (1985). Understanding the drought phenomenon: The role of definitions. Recuperado de http://digitalcommons.unl.edu/droughtfacpub/20

Winsemius, C., Jongman, B., Veldkamp, I. E., Hallegatte, S., Bangalore, M., \& Ward, P. J. (2018). Disaster risk, climate change, and poverty: Assessing the global exposure of poor people to floods and droughts. Environment and Development Economics, 23(3), 328-348. Recuperado de https://doi.org/10.1017/S1355770X17000444

Wisner, B., Blaikie, P., Cannon, T., \& Davis, I. (2003). At risk: Natural hazards, people's vulnerability and disasters ( $2^{\text {nd }}$ ed.). Recuperado de https://www.preventionweb.net/files/670_72351.pdf

Wood, N. (2011). Understanding risk and resilience to natural hazards. Vancouver, USA: U.S. Geological Survey Fact Sheet: (p. 2). Recuperado de http://pubs.usgs.gov/fs/2011/3008/

Yen, B. C. (1971). Risks in hydrologic design of engineering projects, Journal of the Hydraulics Division, 97(9), 1525-1526. Recuperado de https://doi.org/10.1061/JYCEAJ.0002476 
Tecnología y

Ciencias $\stackrel{\unlhd}{\unlhd}$ gua
2022, Instituto Mexicano de Tecnología del Agua

Open Access bajo la licencia CC BY-NC-SA 4.0 (https://creativecommons.org/licenses/by-nc$\mathrm{sa} / 4.0 /)$

Zhang, R., Chen, Z. Y., Xu, L. J., \& Ou, C. Q. (2019). Meteorological drought forecasting based on a statistical model with machine learning techniques in Shaanxi province, China. Science of the Total Environment, 665, 338-346. Recuperado de https://doi.org/10.1016/j.scitotenv.2019.01.431

Zarafshani, K., Sharafi, L., Azadi, H., Hosseininia, G., De-Maeyer, P., \& Witlox, F. (2012). Drought vulnerability assessment: The case of Wheat farmers in Western Iran. Global and Planetary Change, 9899, 122-130. Recuperado de https://doi.org/10.1016/j.gloplacha.2012.08.012 